\title{
Minichromosome maintenance 6 complex component identified by bioinformatics analysis and experimental validation in esophageal squamous cell carcinoma
}

\author{
XUEBING LI ${ }^{1}$, ZHENZHEN REN $^{1}, \mathrm{CHAO}_{\mathrm{XIONG}}{ }^{2}, \mathrm{JIE} \mathrm{GENG}^{1}$, YUQING $\mathrm{LI}^{2}$, \\ CONG LIU ${ }^{1}$, CHUNFENG REN ${ }^{1}$ and HONGCHUN LIU ${ }^{1}$ \\ ${ }^{1}$ Department of Medical Laboratory, First Affiliated Hospital of Zhengzhou University, Zhengzhou, \\ Henan 450052; ${ }^{2}$ Department of Medical Laboratory, The Second Affiliated Hospital of Henan University \\ of Traditional Chinese Medicine, Zhengzhou, Henan 450000, P.R. China
}

Received February 22, 2020; Accepted June 5, 2020

DOI: $10.3892 / o r .2020 .7658$

\begin{abstract}
Esophageal squamous cell carcinoma (ESCC), the main subtype of esophageal cancer (EC), is a common lethal type of cancer with a high mortality rate. The aim of the present study was to select key relevant genes and identify potential mechanisms involved in the development of ESCC based on bioinformatics analysis. Minichromosome maintenance 6 complex component (MCM6) has been identified to be upregulated in multiple malignancies; however, its contributions to ESCC remain unclear. For the purposes of the present study, four datasets were downloaded from the Gene Expression Omnibus (GSE63941, GSE26886, GSE17351 and GSE77861), and the intersection of the differentially expressed genes was obtained using a Venn diagram. The protein-protein
\end{abstract}

Correspondence to: Professor Hongchun Liu, Department of Medical Laboratory, First Affiliated Hospital of Zhengzhou University, 1 Jianshe East Road, Wulibao Street, Erqi, Zhengzhou, Henan 450052, P.R. China

E-mail: xingyunerliu@163.com

Abbreviations: EC, esophageal cancer; ESCC, esophageal squamous cell carcinoma; EAC, esophageal adenocarcinoma; MCM6, minichromosome maintenance 6; GEO, Gene Expression Omnibus; STRING, the search tool for the retrieval of interacting genes; TCGA, The Cancer Genome Atlas; MCODE, molecular complex detection; DAVID, Database for Annotation, Visualization, and Integrated Discovery; PPI, protein-protein interaction; GO, Gene Ontology; BP, biological process; CC, cellular component; MF, molecular function; KEGG, Kyoto Encyclopedia of Genes and Genomes; GEPIA, Gene Expression Profiling Interactive Analysis; GTEx, genotype tissue expression; CI, confidence intervals; HR, hazard ratios; DEGs, differentially expressed genes

Key words: esophageal squamous cell carcinoma, GEO database, bioinformatics analysis, experimental validation, differentially expressed genes, minichromosome maintenance complex component 6 interaction was then constructed, and the modules were verified by Cytoscape, in which the key genes have a high connectivity degree with other genes. Gene Ontology and Kyoto Encyclopedia of Genes and Genomes pathway were subsequently filtered out to analyze the development of ESCC. MCM6, an upregulated gene, was selected and connected with most of the other genes, for further research validation. The expression levels of MCM6 were then assessed using the Oncomine, GEPIA and UALCAN databases and validated in both ESCC tissues samples and cell lines by immunohistochemistry and RT-qPCR. Cell counting kit-8 (CCK-8), flow cytometry, wound healing and Transwell assays were used to determine the proliferation, apoptosis, cell cycle, migration and invasion of ESCC cells. A total of 24 genes were identified by a series of bioinformatics analyses and the results revealed that the genes were associated with DNA replication and cell cycle. Experimental validation revealed that MCM6 expression was significantly elevated in both ESCC tissues and cell lines. The results were consistent with those of bioinformatics analysis. Furthermore, the knockdown of MCM6 inhibited cell proliferation, migration and invasion and promoted cell apoptosis, and made cells arrested in S stage. In summary, the findings of bioinformatics analysis provided a novel hypothesis for ESCC progression. In particular, the aberrantly elevated expression of MCM6 is a potential biomarker for ESCC diagnosis and treatment.

\section{Introduction}

Esophageal cancer (EC), including esophageal squamous cell carcinoma (ESCC) and esophageal adenocarcinoma (EAC) (1), is one of the most lethal and common types of cancers associated with a high morbidity and mortality, posing a public health issue (2-4). The factors involved in ESCC are complex, and include age, sex, stages and body mass index (5-7). In the majority of cases, patients are diagnosed at advanced stages of disease, and thus have passed the point at which treatment may be effective. Even with the assistance of surgery and several other adjuvant therapies, such as chemoradiotherapy, radiotherapy and molecular-targeted therapy, patients with EC 
have a 5 -year survival of $20-25 \%(8,9)$. Although a number of genes are related to the development of ESCC, early diagnosis, treatment and prognosis assessment of ESCC are difficult (10). Therefore, it is of utmost importance to identify novel molecular markers for the early diagnosis and prognosis of ESCC.

Previously, high-throughput microarray analysis, which has yielded numerous clinical data, was considered an efficient tool for determining underlying molecular mechanisms and genetic alterations in cancer progression $(11,12)$. A large portion of these data are freely accessible to researchers and the public; bioinformatics has a number of powerful algorithms, software and databases $(13,14)$. RNA microarrays have been widely applied in cancer diagnosis, metastasis and cancer through gene expression profiling, available in the Gene Expression Omnibus (GEO) database (15). GEO is an open genomics data database which provides clues to the molecular mechanisms underlying the initiation and evolution of ESCC. In the present study, four microarray datasets (GSE63941, GSE26886, GSE17351 and GSE77861) were downloaded from GEO and the shared differentially expressed genes (DEGs) involved in ESCC were investigated using the GEO2R online analysis tool (16). Protein-protein interaction (PPI), Gene Ontology (GO) and Kyoto Encyclopedia of Genes and Genomes (KEGG) analysis were used to preliminary comprehend the molecular mechanisms behind the core genes. Oncomine, Gene Expression Profiling Interactive Analysis (GEPIA) and UALCAN were used to validate the expression levels and prognostic value of MCM6 in ESCC. The results may provide new insight into potential biomarkers for ESCC. Finally, the role of MCM6 in ESCC cell lines was examined.

Maintenance complex components (MCMs) have been identified to play an important role in eukaryotic genome replication (17). During the late M to early G1 phase of the cell cycle, the MCM2-7 complex binds to the origin of DNA replication (18). In eukaryotic cells, the complex plays the role of replicative helicase, which is essential for the initiation and elongation of DNA replication $(19,20)$. MCM6 is a member of the MCM protein complex; a number of studies have verified the abnormal expression of MCM6 and its tumorigenic role in various types of cancer, such as meningiomas, non-small cell lung carcinoma, chondrosarcoma, endometrioid endometrial adenocarcinoma, colorectal cancer (21-25). An elevated MCM6 level has also been reported in serum in hepatocellular carcinoma $(26,27)$. Furthermore, an elevated MCM6 expression has been shown to be associated with a high risk of recurrence in meningioma, which suggests that MCM6 is a promising prognostic marker (21). However, little is known regarding its role in ESCC.

The aim of the present study was to use bioinformatics methods obtained from the GEO database to identify hub genes involved in the progression of ESCC. Subsequently, its expression and molecular functions were validated by performing a series of experiments.

\section{Materials and methods}

Extraction of microarray gene expression profiles from the GEO database. In total, 4 microarray datasets (GSE63941, GSE26886, GSE17351 and GSE77861), which were related to ESCC based on the platform of GPL570 Affymetrix Human Genome U133 Plus 2.0 Array, were extracted from the GEO database (http://www.ncbi.nlm.nih.gov/gds). The screening criteria for the datasets were as follows: i) Available comparison datasets between ESCC tumor tissues or cell lines and the normal control; ii) pre-operative treatment without esophageal resection and cell lines without drug stimulation; iii) the number of samples in datasets $>5$; iv) datasets included RNA-Seq data. The 4 datasets comprised 78 samples, which included 22 ESCC cell lines, 31 ESCC tissues and 25 normal controls. The present study used data based on the GEO database and thus did not require ethics approval.

Data processing and identification of DEGs. GEO2R, which is an R programming language-based online analysis tool, was used in the 4 profiles, respectively, to identify the DEGs (https://www.ncbi.nlm.nih.gov/geo/geo2r/) (15). The criteria of selection were adjusted $\mathrm{P}$-values $<0.05, \mathrm{P}<0.05$ and $\log 2 \mathrm{FC}$ (fold change) $\mid \geq 1$. Online Venn diagram software (http://bioinformatics.psb.ugent.be/webtools/Venn/) was used to obtain the intersection of the DEGs of the 4 datasets, which was used for the subsequent analysis (28). In addition, genes with multiple probes were averaged or removed.

PPI network and module analysis of DEGs. The search tool for the retrieval of interacting genes (STRING) (http://string-db.org/), an online tool for searching the association between various proteins, was used to extract interacting genes $(29,30)$. DEGs with co-expression coefficients $>0.4$ were extracted from STRING. The associations among these genes were visualized using Cytoscape software (31). The plugin Molecular Complex Detection (MCODE) was designed to extract key modules $(\mathrm{k}$-core $=2$ ), in which the core genes have the highest connectivity degree with other genes.

GO and KEGG pathway enrichment analysis of the core genes. The Database for Annotation, Visualization, and Integrated Discovery (DAVID) (https://david.ncifcrf.gov/), an online platform for annotation, visualization and integrated discovery, was used to investigate the functions and mechanism of the DEGs (32). The analyses in DAVID included GO, which was used to annotate the functions, such as molecular function (MF), cellular component (CC) and biological process (BP) (33), and the KEGG pathway, which is a sophisticated database for genomic information and high-order functional information (34). The threshold values were $\mathrm{P}<0.05$, and the most enrichment GO annotation and KEGG pathway were listed.

Oncomine analysis of gene expression. Oncomine (https://www.oncomine.org/resource/main.html), a platform for collecting, analyzing and delivering cancer data, including 264 independent datasets, was used to analyze the DNA or RNA sequences for biomedical research (35). Oncomine was used to analyze the expression level of MCM6 in various tumors and different subtypes of EC. For MCM6 expression in subtypes of EC, the terms queried were set as follows: 1, Gene: MCM6; 2, analysis type: Esophageal Cancer vs. Normal Analysis; 3, Data Type: mRNA. 
GEPIA analysis of gene expression. GEPIA (http:/gepia. cancer-pku.cn/index.html), a newly developed online software, is based on the RNA sequences from Genotype Tissue Expression (GTEx) data and The Cancer Genome Atlas (TCGA) programs, including 9,736 cancer and 8,587 normal samples, and used to explore the expression differences (36). In the present study, GEPIA was used to explore the mRNA expression level with regards to MCM6 between the ESCC and normal esophagus samples, and was also used to examine MCM6 expression in different types of cancer. We entered the gene (e.g., MCM6) in the 'Enter gene name' field and clicked the 'GoPIA' button, which generated the expression profile of MCM6 in all tumors and the corresponding normal tissues. The given gene (MCM6) expression in ESCA was presented in Expression DIY (in the Boxplot tab) with $\log 2 \mathrm{FC}>1$ and $\mathrm{P}$-value $<0.01$ were the cut-off criteria.

UALCANanalysis of gene expression. UALCAN (http://ualcan. path.uab.edu/analysis.html), an interactive resource, can be used to analyze gene transcriptional levels compared to normal samples with relative clinicopathological parameters from the TCGA database, including 31 cancer types with clinical data (37). In the present study, UALCAN was used to examine MCM6 expression in ESCC tissues and its association with clinicopathological parameters. We entered the gene (MCM6) in 'Scan by genes' and selected the TCGA datasets which was the cancer type of interest (e.g., esophageal cancer) and clicked the 'Explore' button. The expression and survival information of entered gene were listed in new links. The expression analysis results provided the relative expression level of interested gene in normal tissues and its subgroups. The survival analysis showed multiple KM-plots which revealed the association of gene expression level and the clinical parameters, such as tumor grade, patient's race and sex.

Patient tissues and cell lines. A total of 68 ESCC tissues and 30 paraffin-embedded normal tissues were collected from the Pathology Laboratory of the First Affiliated Hospital of Zhengzhou University from September, 2018 to February, 2019. The detailed clinicopathological parameters are listed in Table I. The 30 normal tissues were obtained from the corresponding adjacent normal tissues of 68 ESCC tissues diagnosed by routine post-surgery histological examination. Because of missing of part adjacent normal control samples and part clinicopathological parameters, the number of ESCC tissues and normal tissues were not paired completely. Thus, each sample was treated as a separate individual. None of the patients had received any radiotherapy and other treatments prior to surgical resection, and all the patients had signed written informed consent forms. All tissues were diagnosed as ESCC by a post-surgery histological examination.

The present study was approved by the Ethics Committee of the First Affiliated Hospital of Zhengzhou University. Human ESCC cell lines (EC109 and KYSE30) and a normal esophageal epithelial cell line (Het-1A) were purchased from the Shanghai Institute of Life Sciences Cell Bank Center (Shanghai).

Immunohistochemistry. A total of 68 paraffin-embedded cancer tissue sections and 30 corresponding normal tissues, which were cut into $4-\mu \mathrm{m}$ sections and fixed using $4 \%$ paraformaldehyde for $48 \mathrm{~h}$ at room temperature, were selected for immunohistochemical staining. The sections were deparaffinized in xylene and graded alcohols (100, 95, 90, 75 and 70\%), followed by antigen retrieval in citrate buffer. After endogenous peroxidase activity was exhausted with $3 \%$ hydrogen peroxide, the sections were blocked in $10 \%$ goat serum (Sangon Biotech Co., Ltd.) to prevent non-specific staining for $30 \mathrm{~min}$ at room temperature and then washed with phosphate-buffered saline (PBS). Subsequently, anti-MCM6 primary polyclonal antibodies (1:4,000, cat. no. 201683, Abcam) were added overnight at $4^{\circ} \mathrm{C}$, and the sections were then incubated with HRP-labeled goat anti-rabbit secondary antibody (1:100, cat. no. A0208, Beyotime Institute of Biotechnology) at room temperature for $1 \mathrm{~h}$ the following day. The slides were then visualized with 3,3'-diaminobenzidine (DAB) and counterstained with hematoxylin for $3 \mathrm{~min}$ at room temperature. Following dehydrating in alcohols (70, 75, 90, 95 and 100\%) for min each, xylene for $15 \mathrm{~min}$, all at room temperature, the slides were covered with neutral gum. The number of positive cells that exhibited brown color were assessed by two independent pathologists from the Pathology Laboratory of the First Affiliated Hospital of Zhengzhou University (Zhengzhou, China) with no prior knowledge of the patient clinical details, under a light microscope (magnification, x100) and both the staining intensity and extent were considered using Image $\mathrm{J}$ software (version 1.8.0; National Institutes of Health). The final staining quantification was performed by multiplying the intensity scored from 0 to 3 and the extent score from 0 to $100 \%$. The protein expression was classified as positive if the final score was $>1.5$, and negative if the score was $<1.5$ or 1.5 . The antibody used was MCM6 (1:4,000, cat. no. 201683, Abcam). Additionally, the clinical significance was analyzed based on the clinical parameters.

Cell culture. ESCC cell lines and normal esophageal epithelial cells were cultured in Roswell Park Memorial Institute-1640 (RPMI-1640, HyClone; GE Healthcare Life Sciences) supplemented with $10 \%$ fetal bovine serum (FBS, Gibco; Thermo Fisher Scientific, Inc.). For routine culture, the cells were grown in $5 \% \mathrm{CO}_{2}$ at $37^{\circ} \mathrm{C}$. After cell recovery and adherence, cells were passaged every 2 days, and maintained in the logarithmic phase growth. The cells at exponential phase growth were digested with trypsin (Sangon Biotech), and diluted into a suspension of $4 \times 10^{5}$ cells $/ 1$ in a 6 -well plate $(\mathrm{EC} 109)$ or $2.5 \times 10^{5}$ cells $/ 1$ (KYSE30) with RPMI-1640 medium with serum (Sangon Biotech Co., Ltd.). After cell adherence for $12 \mathrm{~h}$, the cells were used for subsequent experiments.

Cell transfection. Small interfering RNAs (siRNAs) targeting MCM6 and siRNA negative control were purchased from RiboBio Co. Ltd. siRNAs were transfected into cells using riboFECT transfection reagent (Changzhou Bio-Generating Biotechnologies Co., Ltd.) according to the manufacturer's protocol. The sequences of the siRNAs used in the present study were as follows: si-MCM6\#1, GGCGCATAGTAGATT TGCA; and si-MCM6\#2, GAAGGAAGCTTTCCGGTTA. After transfection for 24-72 h, the transfection efficiency was confirmed by RT-qPCR and western blot analysis, and transfected cells were collected for further analysis. 
Table I. Association between the clinicopathological parameters and MCM6 expression.

MCM6 expression

\begin{tabular}{|c|c|c|c|c|}
\hline \multirow{2}{*}{ Clinicopathological parameter } & \multirow[b]{2}{*}{ No. } & & \multirow[b]{2}{*}{ P-value } \\
\hline & & Positive $(\mathrm{n}=53)$ & Negative $(\mathrm{n}=15)$ & \\
\hline Age & & & & 0.416 \\
\hline$<60$ years & 30 & 22 & 8 & \\
\hline$\geq 60$ years & 38 & 31 & 7 & \\
\hline Sex & & & & 0.111 \\
\hline Male & 33 & 23 & 10 & \\
\hline Female & 35 & 30 & 5 & \\
\hline TNM stage & & & & 0.179 \\
\hline $\mathrm{I} / \mathrm{II}$ & 50 & 41 & 9 & \\
\hline III/IV & 18 & 12 & 6 & \\
\hline Lymphatic metastasis & & & & $0.049^{\mathrm{a}}$ \\
\hline No & 46 & 39 & 7 & \\
\hline Yes & 22 & 14 & 8 & \\
\hline Infiltration depth & & & & $0.003^{\mathrm{a}}$ \\
\hline Submucosal/superficial layer & 48 & 42 & 6 & \\
\hline Deep muscle/outer layer & 20 & 11 & 9 & \\
\hline
\end{tabular}



Table II. Detailed information of the datasets.

\begin{tabular}{llccllll}
\hline Dataset & Samples & Case/control & Year & Region & Platform & Organism & Contributor \\
\hline GSE63941 & Cell lines & $22 / 4$ & 2014 & Japan & GPL570 & Homo sapiens & Saito (46) \\
GSE26886 & Tissues & $19 / 9$ & 2013 & Germany & GPL570 & Homo sapiens & Wang (47) \\
GSE17351 & Tissues & $5 / 5$ & 2009 & USA & GPL570 & Homo sapiens & Lee (48) \\
GSE77861 & Tissues & $7 / 7$ & 2016 & USA & GPL570 & Homo sapiens & Erkizan (49) \\
\hline
\end{tabular}

$R N A$ extraction and $R T-q P C R$. Total RNA was extracted from the Het-1A, EC109 and KYSE30 cell lines and transfected cell lines using an RNA isolater (Vazyme, Biotech Co., Ltd.). cDNA was synthesized through a $20 \mu$ l reverse transcription system containing $1 \mu \mathrm{g}$ total RNA with a PrimeScript $^{\mathrm{TM}}$ RT reagent kit with gDNA Eraser (Takara Biotechnology Co., Ltd.) according to the manufacturer's protocols. SYBR ${ }^{\circledR}$ Premix Ex Taq ${ }^{\mathrm{TM}}$ II (Takara Biotechnology Co., Ltd.) was employed for qPCR on a LightCycler 480 II Real-Time PCR System (Roche Diagnostics) with GAPDH as an internal control. The PCR cycling conditions were as follows: Pre-denaturation at $95^{\circ} \mathrm{C}$ for $30 \mathrm{sec}$ for $1 \mathrm{cycle}$, then at $95^{\circ} \mathrm{C}$ for $5 \mathrm{sec}, 60^{\circ} \mathrm{C}$ for $30 \mathrm{sec}$ for $40 \mathrm{cycles}$, followed by the melting curve and cooling stage (at $65^{\circ} \mathrm{C}$ for $15 \mathrm{sec}$ ). mRNA levels were determined via the $2^{-\Delta \Delta \mathrm{Cq}}$ method, with GAPDH used for normalization (38). Each extracted sample was placed in 3 wells, and independent experiments were repeated 3 times. The primers used in the present study were: MCM6 forward, 5'-AAGACCTGCCTACCAGACACAA-3' and reverse, 5'-TGACAGTCCAAGCACAGAAAAGT-3'; GAPDH forward, 5'-GAACGGGAAGCTCACTGG-3' and reverse, 5'-GCCTGCTTCACCACCTTCT-3'.
Table III. Number of DEGs in each expression dataset.

\begin{tabular}{lccr}
\hline Dataset & $\begin{array}{c}\text { Upregulated } \\
\text { genes }\end{array}$ & $\begin{array}{c}\text { Downregulated } \\
\text { genes }\end{array}$ & Total \\
\hline GSE63941 & 7,035 & 3,286 & 10,321 \\
GSE26886 & 4,012 & 4,209 & 8,221 \\
GSE17351 & 478 & 259 & 737 \\
GSE77861 & 814 & 740 & 1,554 \\
\hline
\end{tabular}

DEGs, differentially expressed genes.

Protein isolation and western blot analysis. Total proteins were collected from the cells using radioimmunoprecipitation assay lysis buffer (RIPA, Beyotime Institute of Biotechnology), which were supplemented with protease inhibitors on ice for $30 \mathrm{~min}$ and then centrifuged at $12,000 \mathrm{x}$ g for $10 \mathrm{~min}$ at $4^{\circ} \mathrm{C}$ to harvest the supernatant. The protein concentration of the cell lysates was measured using a bicinchoninic acid kit (BCA, Beyotime Institute of Biotechnology). The proteins (15 $\mu \mathrm{g} / \mathrm{lane})$ 

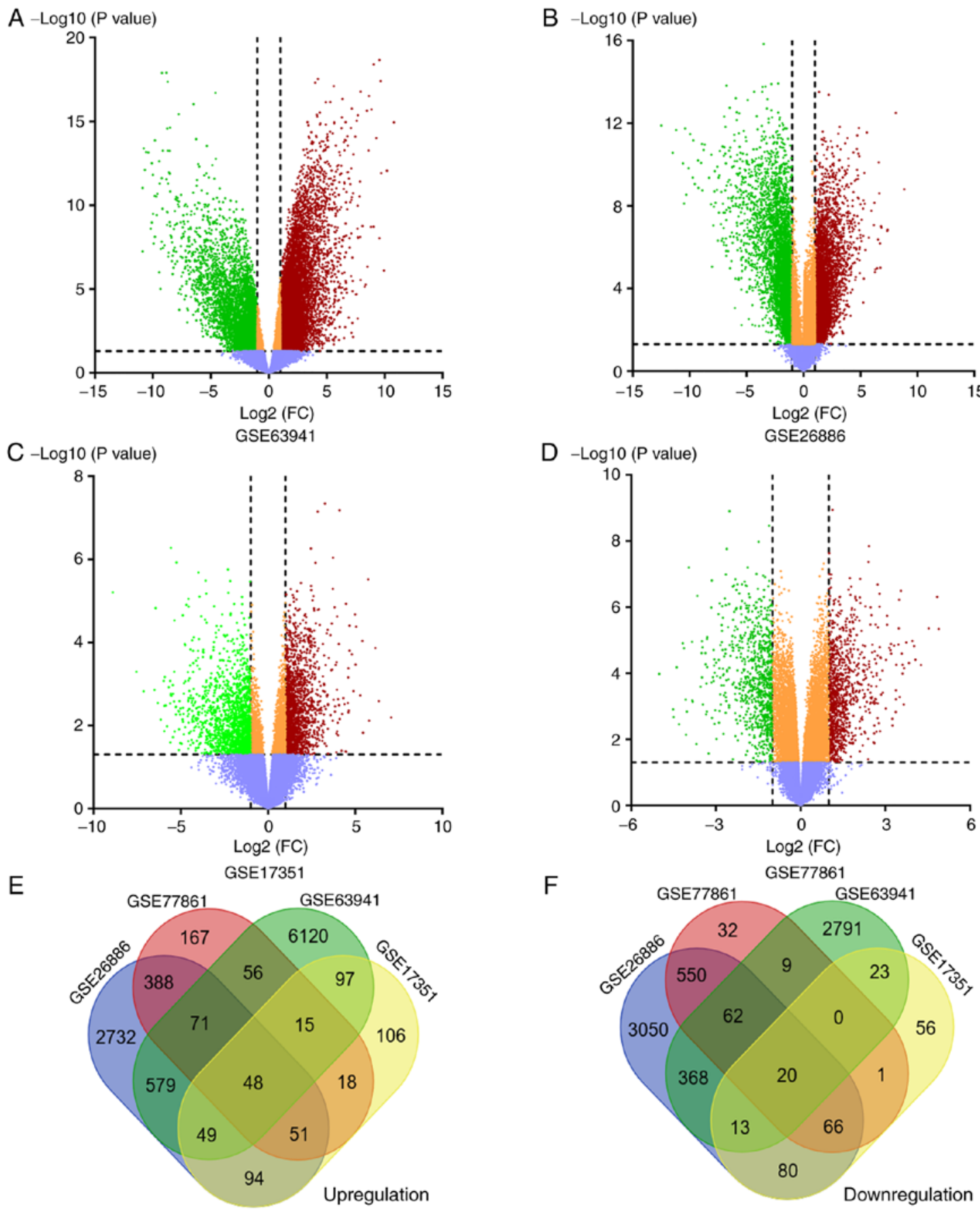

Figure 1. DEGs screened from 4 expression datasets. (A) GSE63941, (B) GSE26886, (C) GSE17351, (D) GSE77861. Upregulated (red-colored spots) and downregulated (green-colored spots) genes in ESCC compared to normal esophageal tissues or cell lines were screened from Gene Expression Omnibus profiles, (E) 48 commonly upregulated DEGs, (F) 20 commonly downregulated DEGs. Different colors represent different datasets and cross areas represent common DEGs. The cut-off criteria were as follows: Adjusted P-values $<0.05, \mathrm{P}<0.05$ and llog2-fold changel $\geq 1$. DEGs, differentially expressed genes; ESCC, esophageal squamous cell carcinoma.

were then separated by sodium dodecyl sulfate polyacrylamide gel electrophoresis (SDS-PAGE) on $10 \%$ gels and transfected to a polyvinylidene fluoride (PVDF) membrane. The PVDF membrane was blocked for $2 \mathrm{~h}$ in $5 \%$ non-fat milk, and then incubated overnight at $4^{\circ} \mathrm{C}$ with primary antibodies and HRP-labeled goat anti-rabbit secondary antibodies (1:5,000, cat. no. A0208, Beyotime Institute of Biotechnology) for $1 \mathrm{~h}$ at room temperature. The protein bands were visualized by chemiluminescence with an imaging system (EMD Millipore) and then analyzed with ImageJ (version 1.8.0; National
Institutes of Health) software. The antibodies were specific for MCM6 (1:2,000, cat. no. 13347-2-AP, ProteinTech Group, Inc.) and GAPDH (1:5,000, cat. no. D110016, Sangon Biotech Co., Ltd.).

Cell Counting Kit-8 (CCK-8) cell proliferation assay. An enhanced Cell Counting Kit-8 (CCK-8, BIOSS) was used to measure the cell proliferative ability. Transfected cells at a density of 3,000 cells/well were inoculated into 96-well plates (Corning, Inc.) which contained $100 \mu 1$ RPMI-1640 with $10 \%$ 


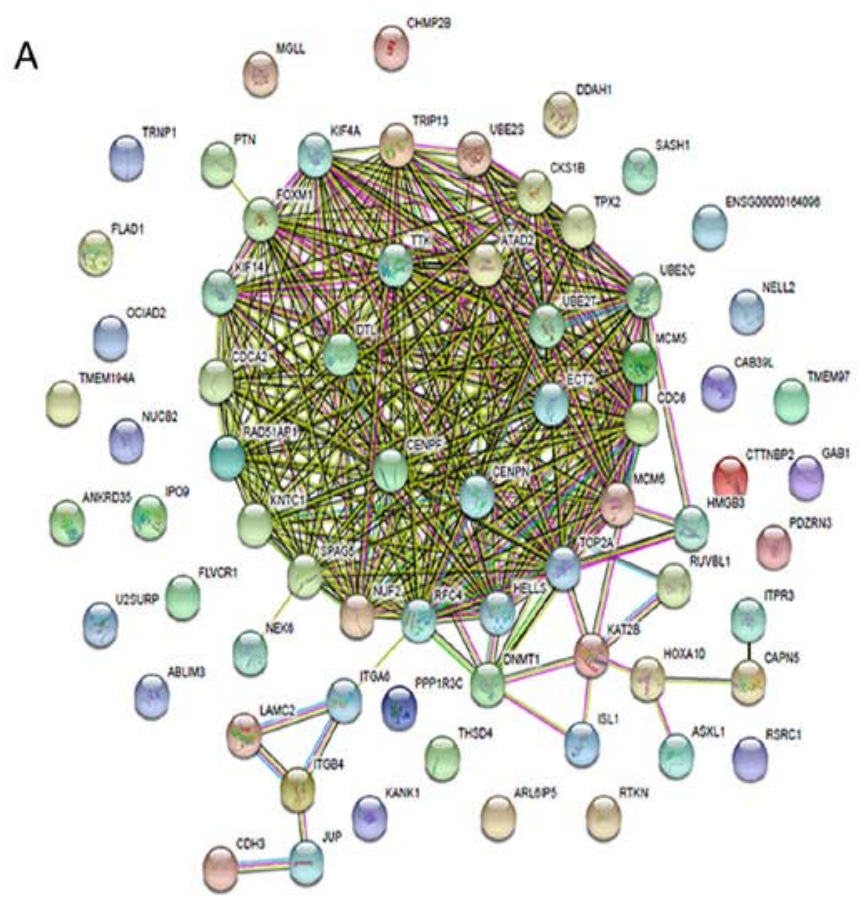

\begin{tabular}{lcc}
\hline Gene & Degree & Regulation \\
\hline RFC4 & 27 & Up \\
TOP2A & 27 & Up \\
CDC6 & 26 & Up \\
UBE2C & 26 & Up \\
TPX2 & 25 & Up \\
MCM6 & 25 & Up \\
TRIP13 & 25 & Up \\
CENPN & 24 & Up \\
RAD51AP1 & 24 & Up \\
DTL & 24 & Up \\
FOXM1 & 24 & Up \\
NUF2 & 24 & Up \\
TTK & 24 & Up \\
CENPF & 23 & Up \\
ECT2 & 23 & Up \\
KNTC1 & 22 & Up \\
SPAG5 & 22 & Up \\
HELLS & 22 & Up \\
KIF14 & 21 & Up \\
KIF4A & 21 & Up \\
CDCA2 & 21 & Up \\
CKS1B & 20 & Up \\
ATAD2 & 20 & Up \\
MCM5 & 20 & Up \\
\hline & & \\
\hline
\end{tabular}

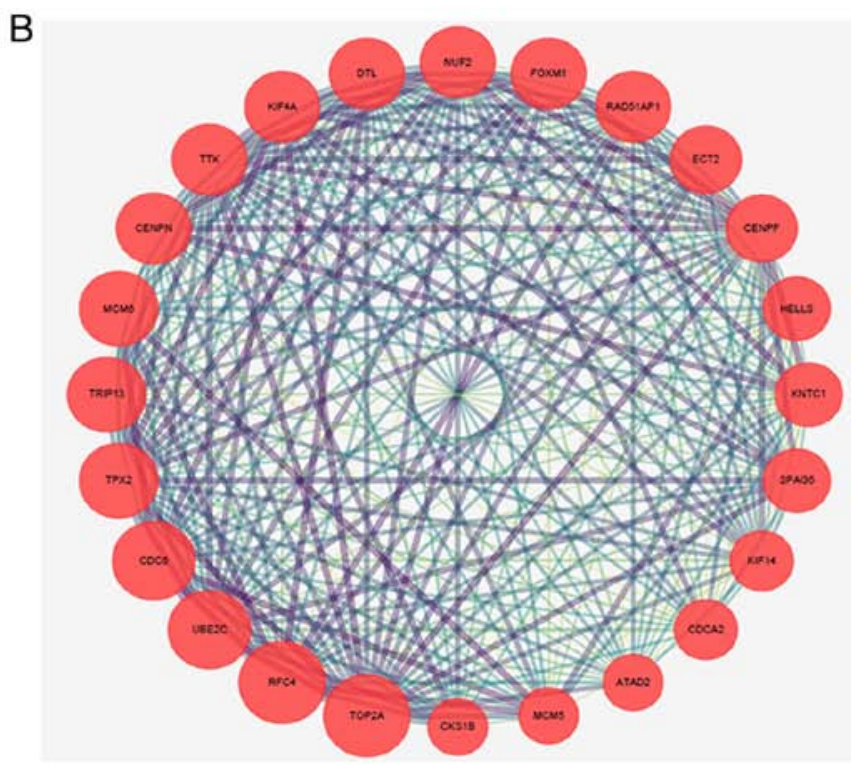

Figure 2. PPI network and the most significant module of DEGs. (A) PPI network of DEGs of the common 68 genes of the 4 datasets shared using STRING. (B) The module with the highest score obtained from Cytoscape; nodes represent key genes and edges represent interactions between genes. (C) Top 24 genes with high connectivity with surrounding genes. $\mathrm{P}<0.01$ was considered to indicate a statistically significant difference. PPI, protein-protein interaction; DEGs, differentially expressed genes.

FBS for 4 days. CCK-8 reagent was added (10 $\mu \mathrm{l} /$ well) to the wells followed by incubation for $2 \mathrm{~h}$ at $37^{\circ} \mathrm{C}$, and the absorbance at $450 \mathrm{~nm}$ was then detected using a microplate reader (SpectraMax M5, Molecular Devices, LLC).

Flow cytometry. Cells transfected with siMCM6 for $48 \mathrm{~h}$ were digested with trypsin without ethylene diamine tetra-acetic acid (EDTA) and the cell suspension was collected and washed with PBS twice. For cell apoptosis analysis, the cell suspension was subjected to Annexin V-APC/7-AAD double staining (KeyGen Biotech) and incubated for $15 \mathrm{~min}$. Apoptotic cells were evaluated within $1 \mathrm{~h}$ by flow cytometry (FACScan; BD Biosciences) according to the manufacturer's instructions. For assessment of the results, mechanically damaged cells were in the upper left quadrant and negative normal cells were in the lower left quadrant; the early apoptotic cells were in the lower right quadrant and late apoptotic cells were in the uppper right quadrant. For cell cycle detection, the cells were fixed with 95\% pre-cold ethanol for $2 \mathrm{~h}$, and then washed with PBS twice. The cells were supplemented with $2 \mu 1 \mathrm{RNase}$ A $(2.5 \mathrm{mg} / \mathrm{ml})$ and $15 \mu \mathrm{l}$ propidium iodide (PI, 15X) (KeyGen Biotech), followed by detection with flow cytometry at $488 \mathrm{~nm}$.

Wound-healing assay. Transfected cells were grown into 6-well plates until $90-100 \%$ confluency at $37^{\circ} \mathrm{C} 5 \% \mathrm{CO}_{2}$. Artificial wound tracks were created using a $200 \mu$ l pipette 
Table IV. Annotation of DEGs.

\begin{tabular}{|c|c|c|c|c|c|}
\hline From & To & Species & Gene name & Degree & Regulation \\
\hline RFC4 & 5984 & Homo sapiens & Replication factor $\mathrm{C}$ subunit 4 & 27 & Up \\
\hline TOP2A & 7153 & Homo sapiens & Topoisomerase (DNA) II alpha & 27 & Up \\
\hline CDC6 & 990 & Homo sapiens & Cell division cycle 6 & 26 & Up \\
\hline UBE2C & 11065 & Homo sapiens & Ubiquitin conjugating enzyme E2 C & 26 & Up \\
\hline TPX2 & 22974 & Homo sapiens & TPX2, microtubule nucleation factor & 25 & Up \\
\hline MCM6 & 4175 & Homo sapiens & Minichromosome maintenance complex component 6 & 25 & Up \\
\hline TRIP13 & 9319 & Homo sapiens & Thyroid hormone receptor interactor 13 & 25 & Up \\
\hline CENPN & 55839 & Homo sapiens & Centromere protein $\mathrm{N}$ & 24 & Up \\
\hline RAD51AP1 & 10635 & Homo sapiens & RAD51-associated protein 1 (RAD51AP1) & 24 & Up \\
\hline DTL & 51514 & Homo sapiens & Denticleless E3 ubiquitin protein ligase homolog & 24 & Up \\
\hline FOXM1 & 2305 & Homo sapiens & Forkhead box M1 & 24 & Up \\
\hline NUF2 & 83540 & Homo sapiens & NUF2, NDC80 kinetochore complex component & 24 & Up \\
\hline TTK & 7272 & Homo sapiens & TTK protein kinase & 24 & Up \\
\hline CENPF & 1063 & Homo sapiens & Centromere protein $\mathrm{F}$ & 23 & Up \\
\hline ECT2 & 1894 & Homo sapiens & Epithelial cell transforming 2 & 23 & Up \\
\hline KNTC1 & 9735 & Homo sapiens & Kinetochore-associated 1 & 22 & Up \\
\hline SPAG5 & 10615 & Homo sapiens & Sperm-associated antigen 5 & 22 & Up \\
\hline HELLS & 3070 & Homo sapiens & Helicase, lymphoid-specific & 22 & Up \\
\hline KIF14 & 9928 & Homo sapiens & Kinesin family member 14 & 21 & Up \\
\hline KIF4A & 24137 & Homo sapiens & Kinesin family member $4 \mathrm{~A}$ & 21 & Up \\
\hline CDCA2 & 157313 & Homo sapiens & Cell division cycle-associated 2 & 21 & Up \\
\hline CKS1B & 1163 & Homo sapiens & CDC28 protein kinase regulatory subunit $1 \mathrm{~B}$ & 20 & Up \\
\hline ATAD2 & 29028 & Homo sapiens & ATPase family, AAA domain containing 2 & 20 & Up \\
\hline MCM5 & 4174 & Homo sapiens & Minichromosome maintenance complex component 5 & 20 & Up \\
\hline
\end{tabular}

DEGs, differentially expressed genes.

tube. The cells were then washed by PBS and supplemented with serum-free medium. Cells migrating into the wound area were assessed to compare cell motility every $24 \mathrm{~h}$.

Transwell assay. The Transwell wells (24-well with pore diameter of $0.8 \mu \mathrm{m}$ ) were covered with Matrigel (BD Biosciences) at $37^{\circ} \mathrm{C}$ for $2 \mathrm{~h}$ for cell invasion assay, and without Matrigel for cell migration assays. Transfected cells were collected and resuspended with $200 \mu \mathrm{l}$ medium without serum, and seeded into the upper chamber of a Transwell plate at a density of $1 \times 10^{5} /$ well. The basolateral chamber was supplemented with $650 \mu \mathrm{l}$ medium with $20 \%$ FBS. Following incubation for $36 \mathrm{~h}$ at $37^{\circ} \mathrm{C}$ and $5 \% \mathrm{CO}_{2}$, the cells were fixed with $4 \%$ paraformaldehyde for $10 \mathrm{~min}$ at room temperature and then stained with crystal violet for $30 \mathrm{~min}$ at room temperature. The cells remaining in the upper chamber were removed and the transmembrane cells were quantified using a light microscope (magnification, x100).

Statistical analysis. SPSS 21.0 software and GraphPad Prism 5 were used for statistical analysis. The experiments were repeated $\geq 3$ times, and the results are presented as the means \pm standard deviation (SD). The MCM6 expression between tumor tissues and normal control esophageal tissues were statistically analyzed using an independent sample
Student's t-test. The associations between MCM6 expression and the patient clinicopathological parameters were assessed by Pearson's $\chi^{2}$ test. The differences between two independent groups were analyzed using a Student's t-test, those between $>2$ groups were analyzed by one-way analysis variance and followed by LSD (Least Significant Difference) post hoc test. Survival analysis was examined by a log-rank test. $\mathrm{P}<0.05$ was considered to indicate a statistically significant difference.

\section{Results}

Extraction of DEGs in ESCC from 4 GEO datasets. Four datasets (GSE63941, GSE26886, GSE17351 and GSE77861) were selected from the GEO database. The characteristics of the 4 datasets are presented in Table II. The up- and downregulated genes in each dataset were then determined. According to the threshold of adjusted P-values of $<0.05$, $\mathrm{P}<0.05$ and $\mid \log 2$-fold changel $\geq 1,7,035$ upregulated and 3,286 downregulated genes were identified from GSE63941 (Fig. 1A), 4,012 upregulated and 4,209 downregulated genes were identified from GSE26886 (Fig. 1B), 478 upregulated and 259 downregulated genes were identified from GSE17351 (Fig. 1C), and 814 upregulated and 740 downregulated genes were identified from GSE77861 (Fig. 1D), as summarized in Table III. The overlapping DEGs were identified by creating a 
Table V. Enriched functions analysis of the 24 core genes.

\begin{tabular}{|c|c|c|c|c|}
\hline Category & Term & Count & P-value & Genes \\
\hline GOTERM_BP_DIRECT & GO:0051301 cell division & 12 & $2.98 \mathrm{E}-13$ & $\begin{array}{l}\text { KIF14, CKS1B, CDC6, SPAG5, KNTC1, } \\
\text { NUF2, TPX2, CDCA2, CENPF, UBE2C, } \\
\text { MCM5, HELLS }\end{array}$ \\
\hline GOTERM_BP_DIRECT & $\begin{array}{l}\text { GO:0007067 mitotic nuclear } \\
\text { division }\end{array}$ & 8 & 2.82E-08 & $\begin{array}{l}\text { CENPN, CDC6, KNTC1, NUF2, TPX2, } \\
\text { CDCA2, CENPF, HELLS }\end{array}$ \\
\hline GOTERM_BP_DIRECT & $\begin{array}{l}\text { GO:0007059 chromosome } \\
\text { segregation }\end{array}$ & 6 & 2.98E-08 & $\begin{array}{l}\text { CENPN, SPAG5, NUF2, CDCA2, CENPF, } \\
\text { TOP2A }\end{array}$ \\
\hline GOTERM_BP_DIRECT & GO:0006260 DNA replication & 5 & $5.39 \mathrm{E}-05$ & $\begin{array}{l}\text { CDC6, RFC4, DTL, MCM5, MCM6 } \\
\text { TOP2A }\end{array}$ \\
\hline GOTERM_BP_DIRECT & $\begin{array}{l}\text { GO:0007062 sister chromatid } \\
\text { cohesion }\end{array}$ & 4 & $3.63 \mathrm{E}-04$ & CENPN, KNTC1, NUF2, CENPF \\
\hline GOTERM_CC_DIRECT & GO:0005654 nucleoplasm & 17 & 7.07E-09 & $\begin{array}{l}\text { CDC6, CENPN, CKS1B, KIF4A, } \\
\text { RAD51AP1, DTL, FOXM1, TPX2, ATAD2, } \\
\text { CENPF, UBE2C, MCM5, MCM6, RFC4, } \\
\text { SPAG5, CDCA2, TOP2A }\end{array}$ \\
\hline GOTERM_CC_DIRECT & GO:0005634 nucleus & 17 & $9.12 \mathrm{E}-05$ & $\begin{array}{l}\text { KIF14, CDC6, RAD51 AP1, DTL, FOXM1, } \\
\text { NUF2, KNTC1, TPX2, ATAD2, CENPF, } \\
\text { ECT2, MCM5, MCM6, SPAG5, TOP2A, } \\
\text { HELLS, TRIP13 }\end{array}$ \\
\hline GOTERM_CC_DIRECT & GO:0005737 cytoplasm & 12 & 0.039863 & $\begin{array}{l}\text { CDC6, KIF4A, DTL, SPAG5, FOXM1, } \\
\text { KNTC1, CDCA2, CENPF, TTK, UBE2C, } \\
\text { ECT2, TOP2A }\end{array}$ \\
\hline GOTERM_CC_DIRECT & GO:0005829 cytosol & 10 & 0.015112 & $\begin{array}{l}\text { KIF14, CENPN, CDC6, KIF4A, KNTC1, } \\
\text { NUF2, TPX2, CENPF, UBE2C, ECT2 }\end{array}$ \\
\hline GOTERM_MF_DIRECT & GO:0005515 protein binding & 21 & $2.23 \mathrm{E}-05$ & $\begin{array}{l}\text { KIF14, CDC6, CKS1B, KIF4A, RAD51AP1, } \\
\text { DTL, FOXM1, TPX2, NUF2, KNTC1, TTK, } \\
\text { CENPF, UBE2C, ECT2, MCM5, MCM6, } \\
\text { RFC4, SPAG5, TOP2A, HELLS, TRIP13 }\end{array}$ \\
\hline GOTERM_MF_DIRECT & GO:0005524 ATP binding & 13 & $3.07 \mathrm{E}-08$ & $\begin{array}{l}\text { KIF14, CDC6, KIF4A, RFC4, TPX2, } \\
\text { ATAD2, TTK, UBE2C, TOP2A, MCM5, } \\
\text { HELLS, TRIP13, MCM6 }\end{array}$ \\
\hline GOTERM_MF_DIRECT & $\begin{array}{l}\text { GO:0003682 chromatin } \\
\text { binding }\end{array}$ & 5 & 0.001241 & CENPF, ATAD2, TOP2A, MCM5, HELLS \\
\hline KEGG_PATHWAY & hsa04110:Cell cycle & 4 & $1.10 \mathrm{E}-04$ & CDC6, TTK, MCM5, MCM6 \\
\hline KEGG_PATHWAY & hsa03030:DNA replication & 3 & 3.94E-04 & RFC4, MCM5, MCM6 \\
\hline
\end{tabular}

GO, Gene Ontology; KEGG, Kyoto Encyclopedia of Genes and Genomes.

Venn diagram. A total of 68 genes, including 48 upregulated genes (Fig. 1E) and 20 downregulated genes (Fig. 1F) were shared in the 4 microarrays.

Subsequently, the protein-protein associations between the 68 genes were analyzed using STRING (Fig. 2A) and then visualized using Cytoscape software. The plugin MCODE was used to screen significant modules from the PPI network. The module of the highest score (22.783) was used for the subsequent analysis (Fig. 2B). A total of 24 nodes and 262 edges were visualized in the module. The hub genes were annotated and are listed in Fig. 2C and Table IV. All 24 genes were upregulated and were used for further enrichment analysis.
GO and KEGG pathway enrichment analysis. As for the 24 genes, GO annotation and KEGG pathway analysis were performed in DAVID. As shown in Table V and Fig. 3, GO analysis revealed that the DEGs were mainly enriched in BPs, including GO:0051301-cell division, GO:0007067-mitotic nuclear division, GO:0007059-chromosome segregation, GO:0006260-DNA replication and GO:0007062-sister chromatid cohesion. As for cellular component, the genes were mainly enriched in nucleoplasm and nucleus, and for molecular function, they were enriched in protein, ATP and chromatin binding. KEGG signal analysis demonstrated that the hub genes were significantly enriched in hsa04110: Cell cycle and hsa03030: DNA replication. More importantly, MCM6 was 

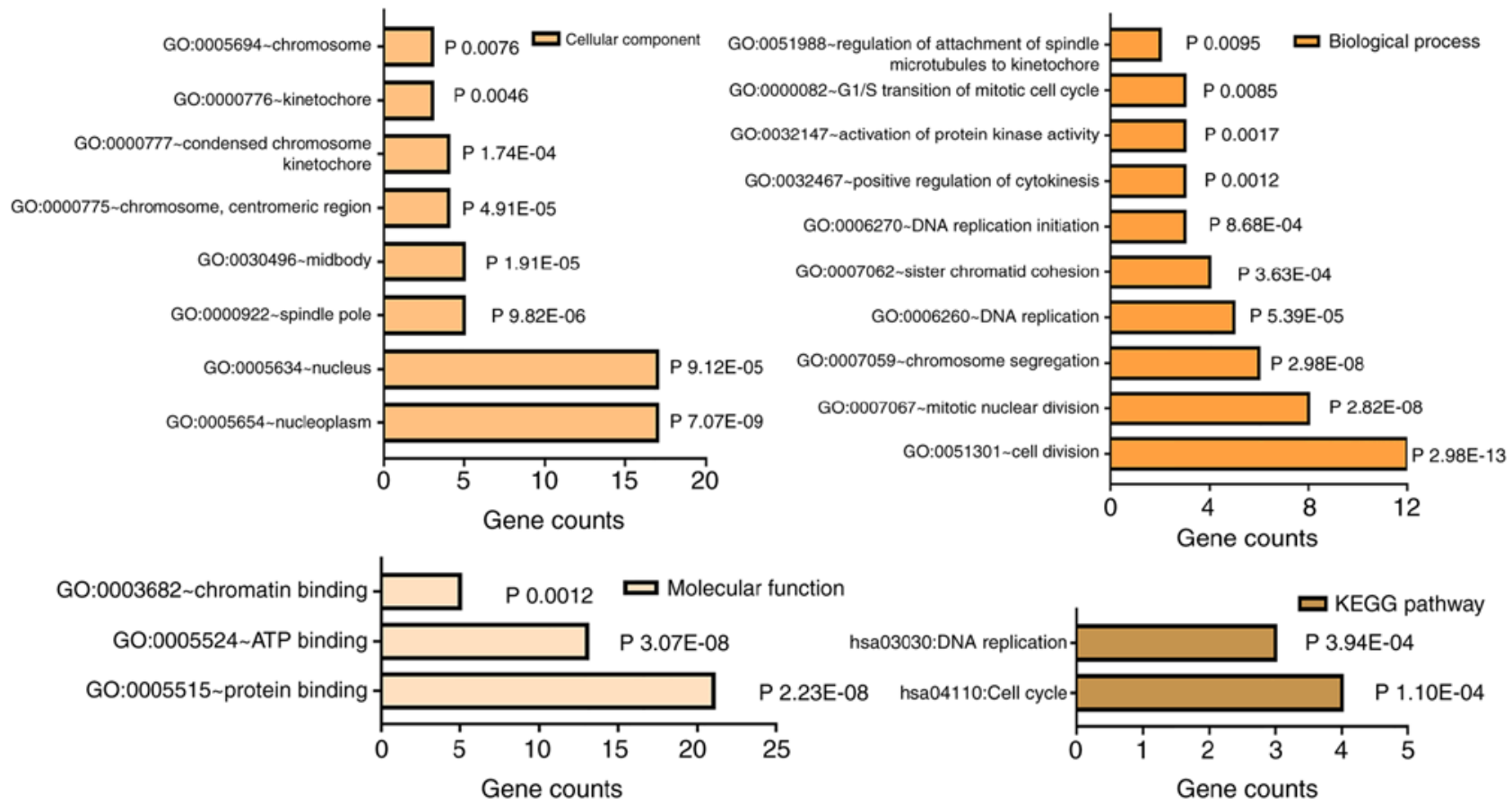

Figure 3. GO and KEGG analysis of 24 upregulated DEGs reveals the main cellular, biological processes, molecular functions and signaling pathways in which they were enriched. GO, Gene Ontology; KEGG, Kyoto Encyclopedia of Genes and Genomes; DEGs, differentially expressed genes.

significantly associated with DNA replication and cell cycle, and was selected for further experimental validation.

Aberrant MCM6 upregulation in human cancers in GEPIA and Oncomine. MCM6 expression was analyzed in various human cancers using the Oncomine database, and the results revealed that MCM6 was upregulated in the majority of solid tumors, including breast, liver, bladder and lung cancer (Fig. 4A). Another analysis in GEPIA also revealed similar results, with the exception of kidney chromophobe and acute myeloid leukemia (Fig. 4B). Both analyses in GEPIA (Fig. 4C) and Oncomine (Fig. 4D and E) revealed upregulated MCM6 expression in ESCC compared with that in normal esophagus tissues.

Additionally, the expression of MCM6 in subtypes of EC, including ESCC, EAC and Barrett's esophagus, were explored. Although the results differed according to the subtype, the higher expression of MCM6 in ESCC was consistent with our bioinformatics analysis (Table SI).

Validation of MCM6 expression in UALCAN. To avoid the limitation of the low number of samples and the short follow-up time, the transcription level of MCM6 was also explored using the UALCAN website, which was based on 31 cancer types of the TCGA database, including 95 squamous cell carcinoma, 89 adenocarcinoma and 11 normal tissues for multivariate regression analysis. The MCM6 mRNA level was significantly elevated in EC tissues compared to normal tissues in the UALCAN website (Fig. 4F). Moreover, no significant association was found between MCM6 expression and the sex of the patients (Fig. 4I). Of note, patients with grade 2 and 3 disease exhibited a higher MCM6 expression than patients with grade 1 disease, although the differences between grade 1 and grade 2 or 3 were not significant $(P>0.05)$; however, significant differences were observed between grades 2 and $3(\mathrm{P}<0.05)$ (Fig. 4G). Moreover, the results revealed that MCM6 expression in all fields, Caucasian, Asian and African-American, was higher in tumor compared to normal tissues, and the MCM6 level in Asians was higher than that of Caucasians $(\mathrm{P}<0.05)$ (Fig. 4H).

MCM6 expression is upregulated in ESCC tissues and cell lines as shown by IHC and RT-qPCR. To further validate the expression level of MCM6, the MCM6 protein level was examined in ESCC tissues by IHC (Fig. 5A). Similar to the results of bioinformatics analysis, the MCM6 protein level in ESCC tissues was significantly higher than that of matched normal tissues (Fig. 5B). IHC revealed that MCM6 was mainly localized in the nucleus. A higher positive ratio was also detected in ESCC tissues (76.5\%) compared to adjacent non-tumor tissues (26.7\%) $(\mathrm{P}<0.001$; Fig. 5C).

Additionally, the association between the MCM6 expression status and ESCC clinicopathological features was explored, and statistical analysis revealed that the positive staining ratio of MCM6 was significantly associated with lymphatic metastasis and infiltration depth (Table I). However, the association between MCM6 expression and age, sex and TNM stage exhibited no significance $(\mathrm{P}>0.05)$.

In order to further verify MCM6 expression in ESCC cell lines, EC109 and KYSE30 were introduced. A high increase in the MCM6 mRNA level was observed in ESCC cells compared to normal esophageal epithelial cells (Het-1A) (Fig. 5D). The results of RT-qPCR revealed that the change in MCM6 mRNA expression was similar to the IHC results and the former bioinformatics analysis.

Silencing of MCM6 decreases cell survival. To explore the possible effects of MCM6 on the cell phenotype, two siRNAs 
A

\begin{tabular}{|c|c|}
\hline Analysis type by cancer & $\begin{array}{l}\text { Cancer } \\
\text { vs. } \\
\text { normal }\end{array}$ \\
\hline Bladder cancer & 1 \\
\hline Brain and CNS cancer & 3 \\
\hline Breast cancer & 2 \\
\hline Cervical cancer & 4 \\
\hline Colorectal cancer & 6 \\
\hline Esophageal cancer & 2 \\
\hline Gastric cancer & 1 \\
\hline Head and neck cancer & 3 \\
\hline Kidney cancer & \\
\hline Leukemia & 1 \\
\hline Liver cancer & 3 \\
\hline Lung cancer & 5 \\
\hline Lymphoma & \\
\hline Melanoma & 1 \\
\hline Myeloma & 1 \\
\hline Other cancer & 5 \\
\hline Ovarian cancer & 3 \\
\hline Pancreatic cancer & \\
\hline Prostate cancer & \\
\hline Sarcoma & 9 \\
\hline Significant unique analyses & \begin{tabular}{l|l}
49 & 4
\end{tabular} \\
\hline Total unique analyses & 450 \\
\hline
\end{tabular}

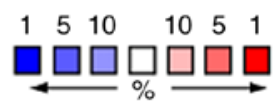

B

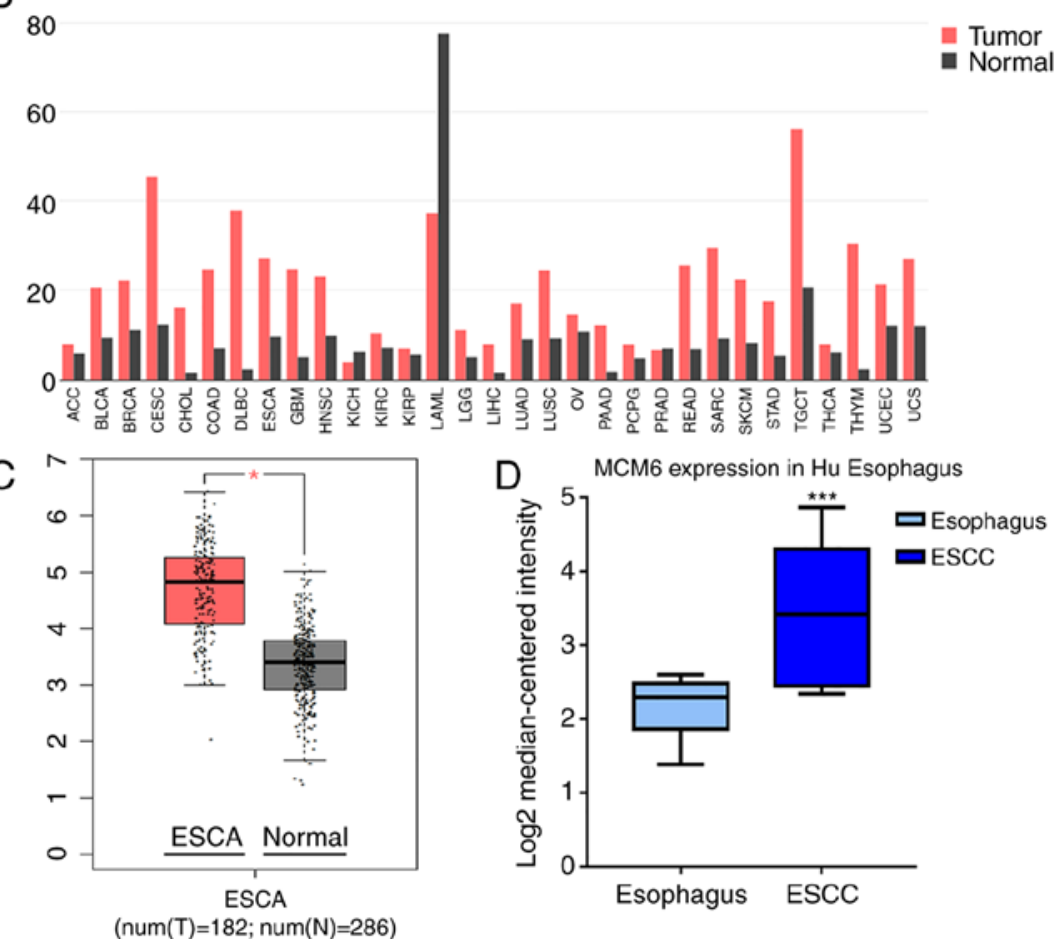

G MCM6 expression in ESCA base on tumor grade
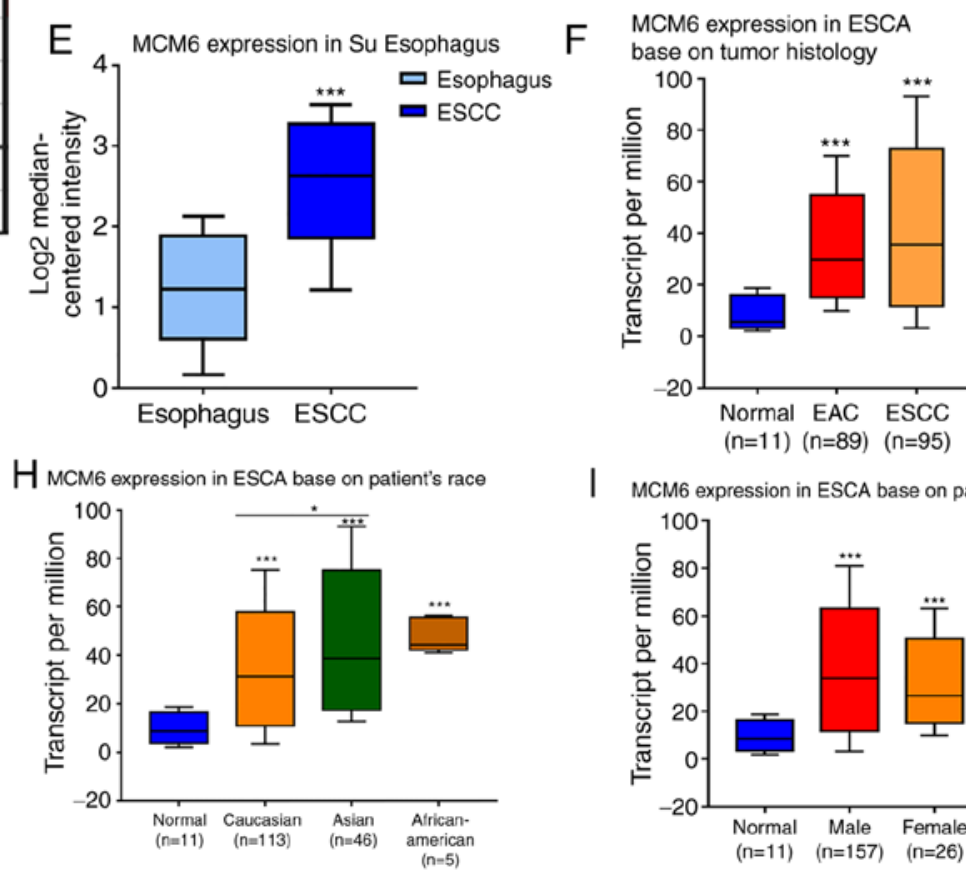

I MCM6 expression in ESCA base on patient's gender

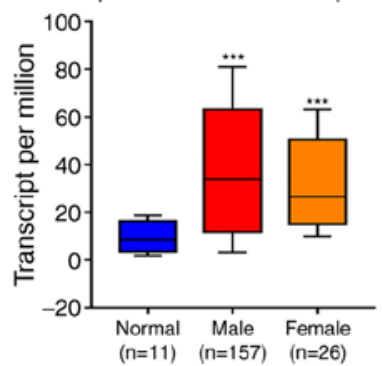

Figure 4. Expression analysis of MCM6. (A) Expression of MCM6 in different types of human tumors. The graphic obtained from Ocomine indicates the number of datasets that were statistically significant $(\mathrm{P}<0.01)$. Red represents mRNA overexpression and blue represents the downregulated expression of MCM6 (cancer vs. normal tissue). The threshold was designed using the following parameters: P-value of 1E-4, fold change of 2, and gene ranking of $10 \%$, (B) Expression of MCM6 in different types of human tumors by GEPIA analysis. (C) Aberrant gain of expression of MCM6 in ESCA compared to normal esophagus tissues by GEPIA analysis. "P<0.05. (D) Gain of expression of MCM6 in ESCC compared to normal esophagus in the Hu et al (51) dataset by Oncomine analysis. ${ }^{* * *} \mathrm{P}<0.001$. (E) Gain of expression of MCM6 in ESCC compared with normal esophageal tissue in the Su et al (50) dataset by Oncomine analysis. ${ }^{* * *} \mathrm{P}<0.001$. (F) Relative MCM6 expression in ESCC and EAC by UALCAN analysis. (G) Tumor grade, (H) patient race, (I) patient sex (also by UALCAN analysis). " $\mathrm{P}<0.05$ and ${ }^{* * *} \mathrm{P}<0.001$ (the first layer asterisk above the bar represents comparison with the normal group, and the asterisk above the secondary line represents the comparison between corresponding groups that were covered by the line). MCM6, minichromosome maintenance 6 complex component; ESCC, esophageal squamous cell carcinoma.

specifically targeting MCM6 were designed, and transfected into EC109 and KYSE30 cells. Cells were collected, and total RNA and protein were isolated for RT-qPCR and western blot analysis to detect the silencing efficiency. Results of the western blot analysis revealed that the MCM6 protein expression level decreased compared with the blank and negative groups (Fig. 5E and F). The results of RT-qPCR revealed a similar tendency in the mRNA expression level (Fig. 5G). 
A


B
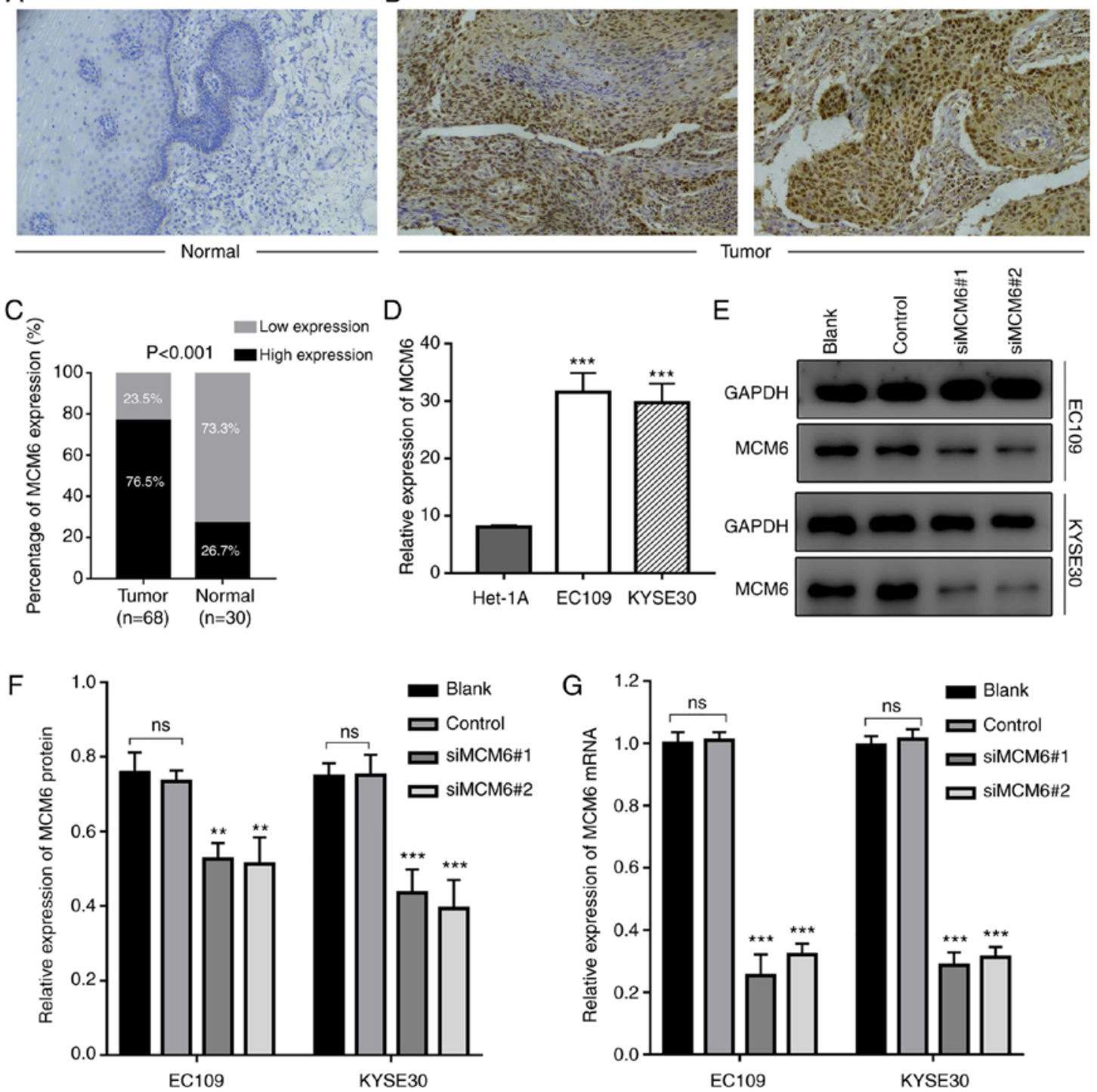

Figure 5. Expression of MCM6 in tissues and cell lines, and transfection efficiency detection. (A) Negative staining of MCM6 in normal esophageal tissues (magnification, x100) (negative). (B) Strong expression in ESCC tissues (positive). (C) MCM6 expression levels were compared among ESCC and paired normal tissues $(\mathrm{P}<0.05)$. (D) Expression of MCM6 in ESCC cell lines analyzed by RT-qPCR. (E and F) Expression of MCM6 was measured by western blot analysis in ESCC cell lines. (G) Expression of MCM6 in ESCC cell lines transfected with siMCM6\#1 and siMCM6\#2. ${ }^{* *} \mathrm{P}<0.01,{ }^{* * *} \mathrm{P}<0.001 . \mathrm{MCM} 6$, minichromosome maintenance 6 complex component; ESCC, esophageal squamous cell carcinoma.

To determine the effect of MCM6 on cell proliferation, the CCK-8 assay was performed. The proliferation rate of the cells transfected with siMCM6\#1 and siMCM6\#2 was decreased compared with the control group, suggesting that the downregulation of MCM6 inhibited the cell proliferation rate $(\mathrm{P}<0.05)$ (Fig. 6A). The cell cycle distribution in each group was detected by flow cytometry, and the results showed that the number of cells in the S stage were increased and those in the G2 stage decreased in the siMCM6\#1 and siMCM6\#2 groups $(\mathrm{P}<0.05)$; however, no differences were observed in the number of cells in the G1 stage in each group. The results confirmed that cells were arrested in the S stage following siMCM6 transfection, which indicated that the knockdown of MCM6 inhibited DNA reduplication activity, thereby inhibiting cell proliferation (Fig. 6B).

The apoptotic rates in the siMCM6\#1 and siMCM6\#2 groups increased relative to the negative control group. The results revealed that the knockdown of MCM6 promoted the apoptosis of ESCC cells (Fig. 6C).

Downregulation of MCM6 inhibits cell motility. Cell motility, including cell migration and invasion, was evaluated using wound-healing and Transwell assays. The wound-healing assay revealed that the negative control cells exhibited a more rapid wound closure rate than the knockdown group, suggesting that the migratory ability was significantly suppressed after MCM6 was silenced (Fig. 7A and B). Similarly, as shown by Transwell assay, the number of migrating (Matrigel-uncoated) (Fig. 7C) or invading (Matrigel-coated) (Fig. 7D) cells in the bottom chamber evidently decreased compared to the negative control group following the knockdown of MCM6. These results suggested that the knockdown of MCM6 significantly inhibited ESCC cell migration and invasion. 
A

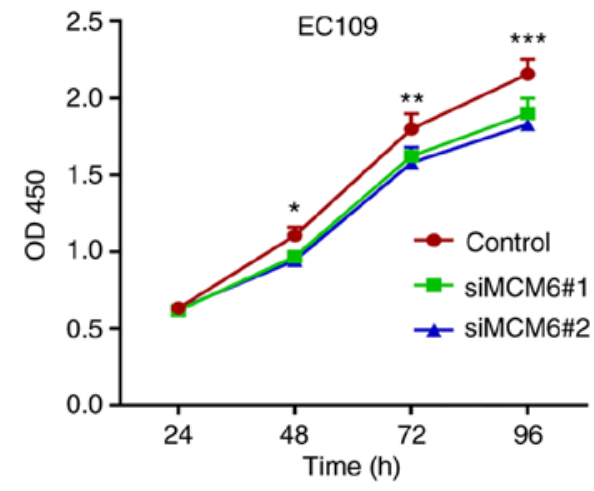

B
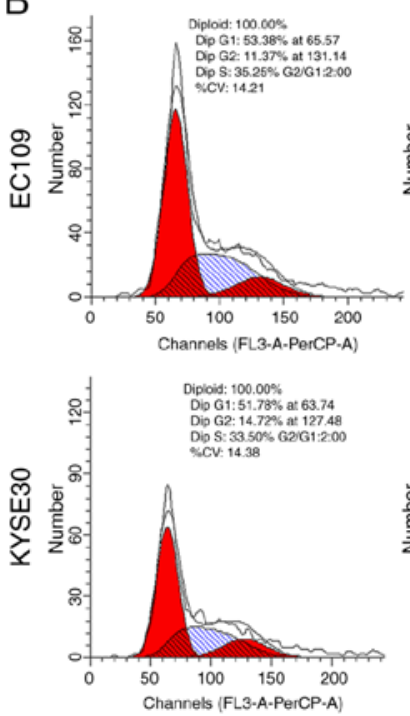

C
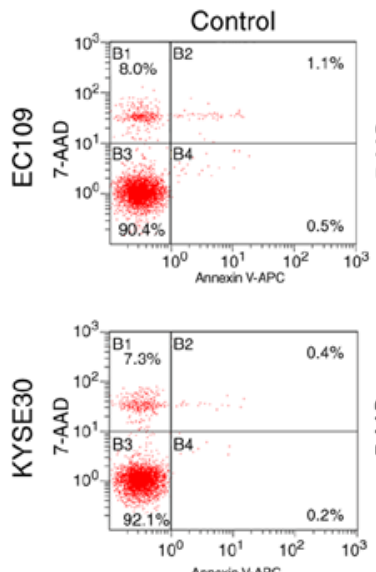

siMCM6\#1


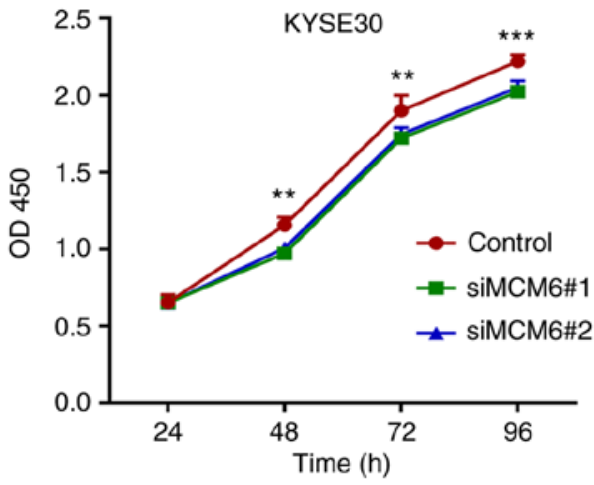

siMCM6\#2


KYSE30
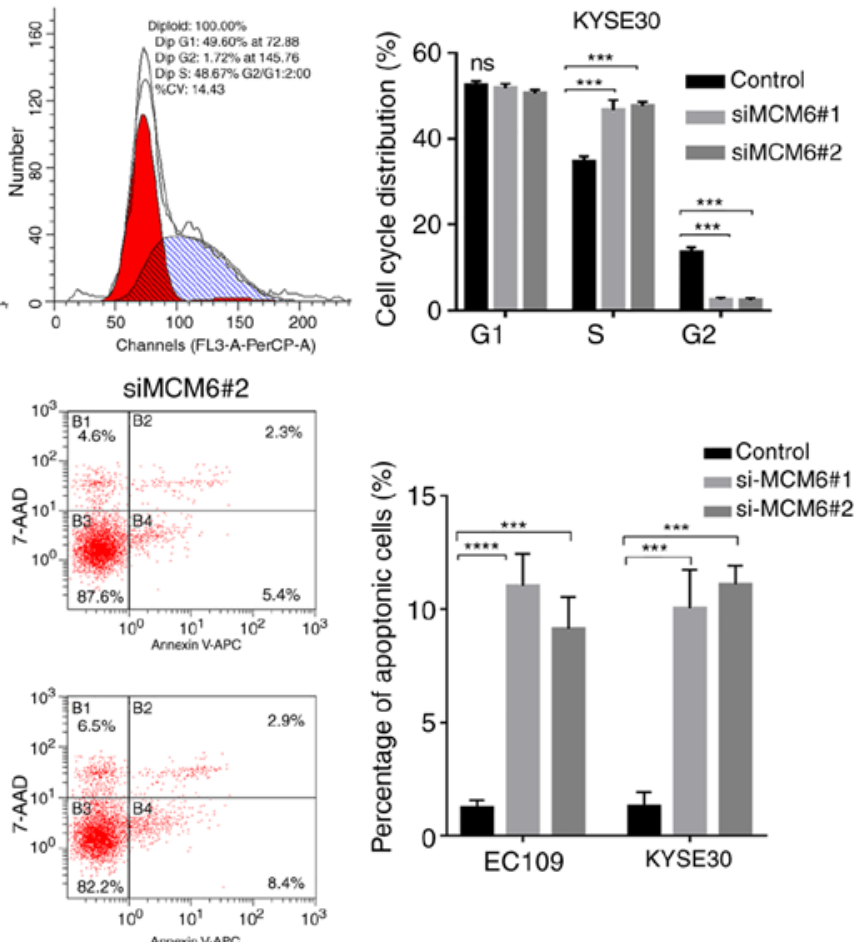

Figure 6. Downregulation of MCM6 suppresses the proliferation of ESCC cells and promotes cell apoptosis in vitro. (A) Proliferation of EC109 and KYSE30 was impaired by the silencing of MCM6, as exemplified by CCK-8 assay. (B) Cells were arrested at the S phase after EC109 and KYSE30 cells were transfected with siMCM6. (C) Number of apoptotic cells increased in the transfected groups in which EC109 and KYSE30 cells were transfected with siMCM6, as analyzed by flow cytometry. All experiments were repeated 3 times independently and presented figures are the most representative figures. ${ }^{*} \mathrm{P}<0.05,{ }^{* *} \mathrm{P}<0.01$, ${ }^{* * *} \mathrm{P}<0.001$ and $^{* * * *} \mathrm{P}<0.0001$. MCM6, minichromosome maintenance 6 complex component; ESCC, esophageal squamous cell carcinoma.

\section{Discussion}

ESCC is associated with an extremely poor prognosis attributed to its invasive and metastatic tendency. Due to the lack of effective therapeutic strategies, it is imperative to develop a therapeutic target to improve the survival rate. Although current molecular targeted therapies have shown promise for the treatment of ESCC, patient prognosis remains poor (8). The aim of the present study was to identify novel biomarkers and therapeutic targets for ESCC using bioinformatics analysis.

Bioinformatics, which combines computer science and life science, aids in the elucidation of underlying molecular mechanisms using the theories of computer science, statistics and biological science, and reduces time and experimental expense $(39,40)$. High-throughput gene chip technologies are widely used to elucidate the mechanisms underlying the progression of ESCC, which provides an 

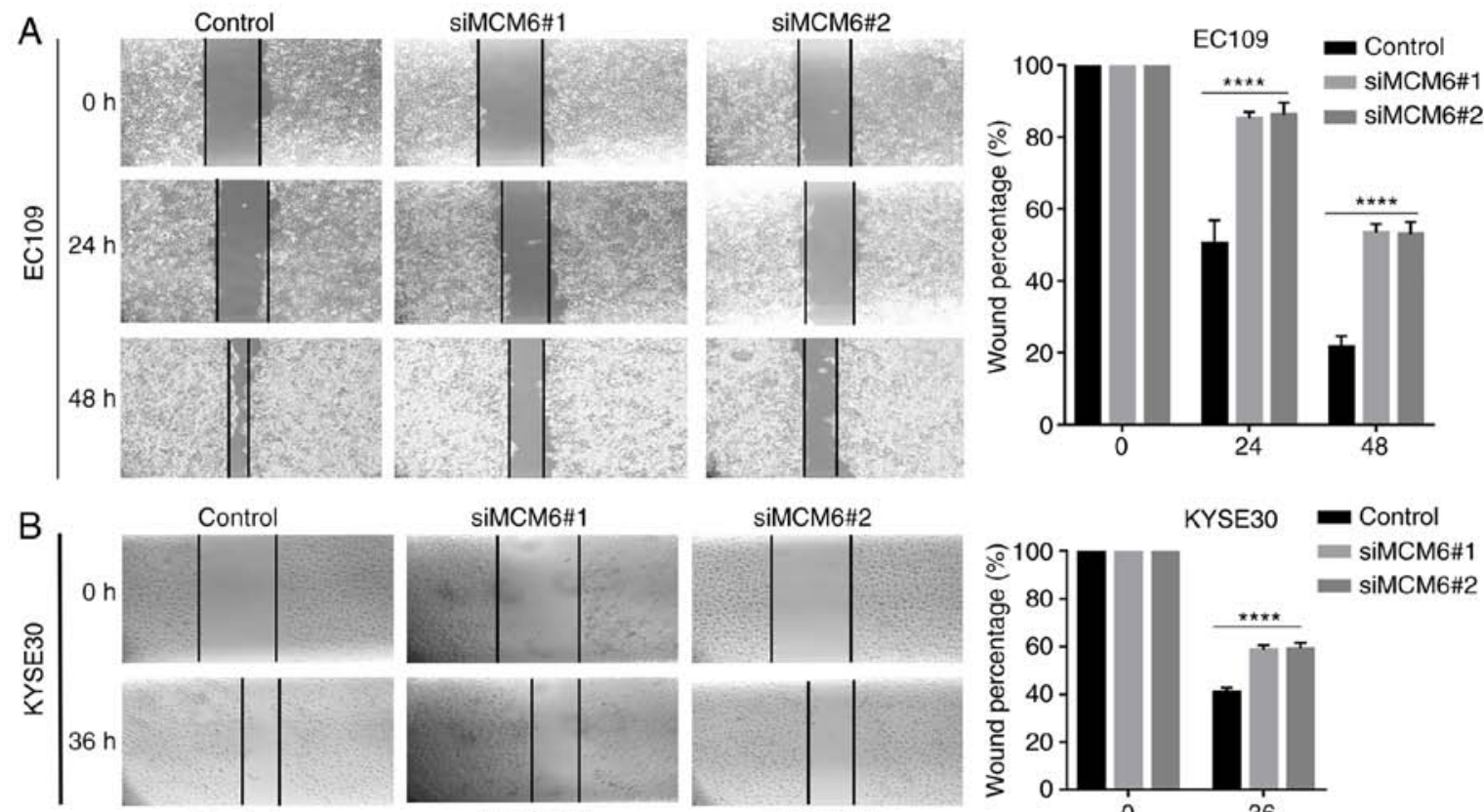

siMCM6\#2
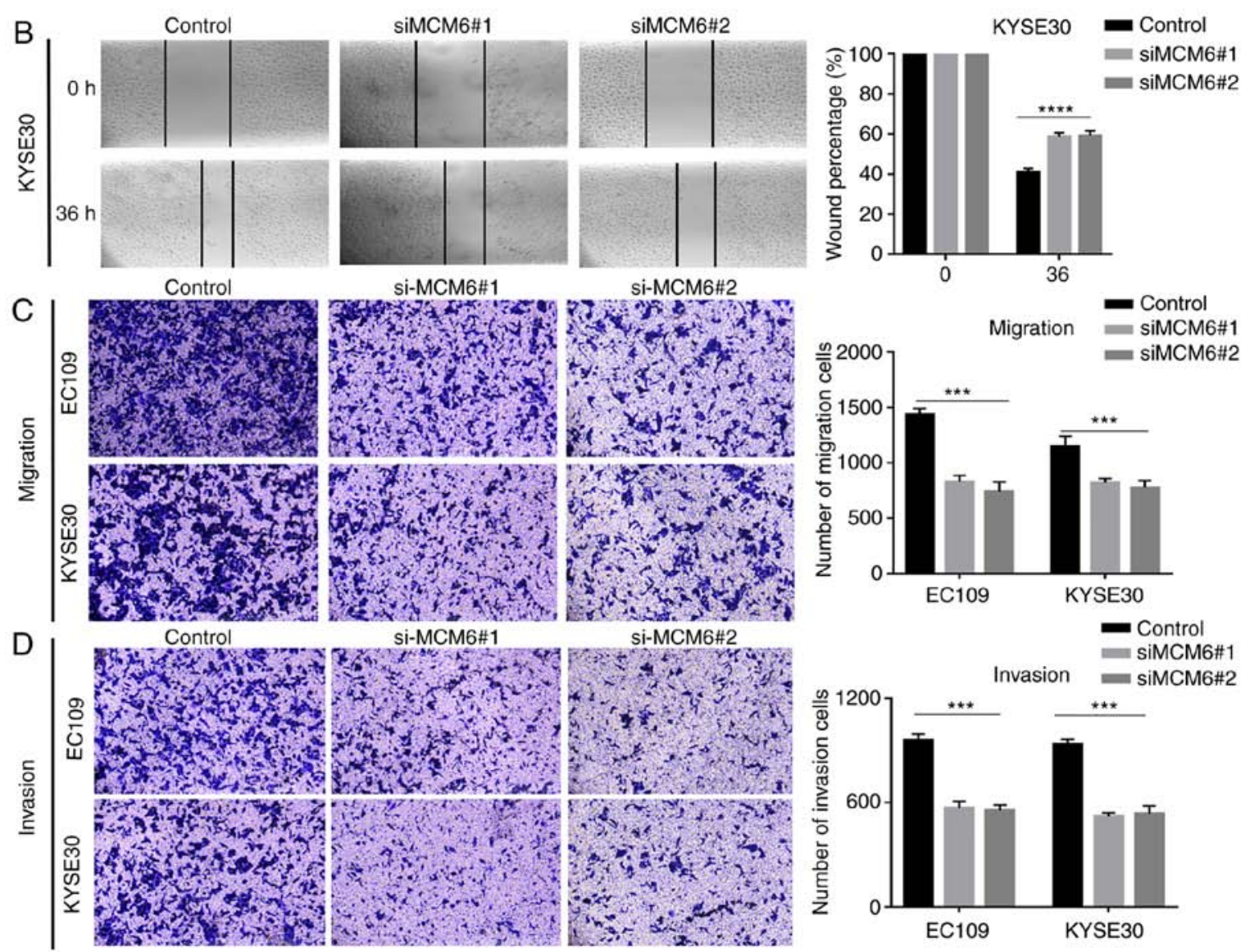

Figure 7. Downregulation of MCM6 suppresses the migration and invasion of ESCC cells. (A and B) Migration was attenuated after MCM6 was knocked down in EC109 and KYSE30 cell lines, as detected by wound-healing assays. (C) Similarly, cell migratory ability was also detected, and the results revealed that cell migration was inhibited when MCM6 was silenced in EC109 and KYSE30 cell lines, as evaluated by Transwell assay (Matrigel-uncoated). (D) Invasion was inhibited when MCM6 was silenced in EC109 and KYSE30 cell lines, as evaluated by Transwell assay (Matrigel-coated). All experiments were repeated 3 times independently and presented figures were the most representative figures. ${ }^{* * *} \mathrm{P}<0.001$ and ${ }^{* * * *} \mathrm{P}<0.001$. MCM6, minichromosome maintenance 6 complex component; ESCC, esophageal squamous cell carcinoma.

effective and innovative approach for the diagnosis, treatment and prevention of ESCC. The GEO database, which can be downloaded for free, is an open dataset, and provides the webpage analysis tool (GEO2R) for the screening of DEGs by GEO query and Limma package. In the present study, 4 mRNA datasets were extracted, including 22 ESCC cell lines, 31 ESCC tissues and 25 normal controls, and 68 core genes were identified (48 upregulated and 20 downregulated genes) shared among the 4 GEO datasets on ESCC by GEO2R. The 68 DEGs were then explored using STRING and Cytoscape and PPI network was generated, which comprised a key clustering module using the MCODE plugin. The module consisted of 24 genes with the highest score (22.783), and the top 24 genes (which have the highest number of connections with surrounding genes), included RFC4, TOP2A, CDC6, UBE2C, TPX2, MCM6, TRIP13, CENPN, RAD51 AP1, DTL, FOXM1, NUF2, TTK, CENPF, ECT2, KNTC1, SPAG5, HELLS, KIF14, KIF4A, CDCA2, CKS1B, ATAD2 and MCM5. MCM6 exhibited great connectivity with other genes. Functional GO annotation revealed that the genes were enriched in cell division, mitotic nuclear division, chromosome segregation, DNA replication and sister chromatid cohesion. KEGG enrichment analysis revealed a significant association with cell 
cycle and DNA replication. These results suggested that the genes may affect ESCC progression by regulating cell division, mitotic nuclear division and DNA replication, and the DEGs may be linked to ESCC progression through the cell cycle pathway. Numerous gene chips and studies on ESCC have aimed to elucidate the genes involved in ESCC progression. Previous findings have also validated key transcription factors involved in the development of ESCC, including cell cycle and DNA replication $(41,42)$, which also suggest that MCM6 exhibits elevated expression and good connectivity with surrounding genes.

MCM6 is a highly conserved MCM protein that is essential for the initiation of eukaryotic genome replication and may be involved in the recruitment of other DNA replication-related proteins. It has been reported that MCM6 is upregulated in various types of cancer, such as non-small cell lung carcinoma, hepatocellular carcinoma and meningiomas $(21,22,26)$. Liu et al (26) verified the upregulated expression of MCM6 in hepatocellular carcinoma and its association with tumor number, early recurrence and liver cirrhosis. However, the expression of MCM6 in ESCC remains obscure. In the present study, MCM6 expression was investigated in ESCC using bioinformatics analysis.

Firstly, in order to further validate aberrant MCM6 expression in EC using bioinformatics tools, Oncomine, UALCAN and GEPIA were also utilized to examine the expression level of MCM6. The results revealed the elevated expression of MCM6 in ESCC compared to normal tissues, which was consistent with the former bioinformatics analysis. TCGA data indicated that the expression of MCM6 was associated with the grade of the disease and the ethnicity of the patients with ESCC. IHC staining, which was conducted on 68 ESCC samples also confirmed the gain of expression of MCM6 in ESCC tissues, and a high expression ratio (76.5\%) in ESCC was observed vs. the low ratio $(26.75 \%)$ in normal tissues. Moreover, analysis of the clinical parameters revealed that MCM6 expression was associated with lymphatic metastasis and infiltration depth, which was inconsistent with our bioinformatics analysis due to different patient samples. Subsequently, RT-qPCR analysis of ESCC cell lines also confirmed the gain of expression of MCM6. It was thus revealed that MCM6 may be a diagnostic and therapeutic biomarker for ESCC.

Cell proliferation, migration and invasion, as well as apoptosis are the basic life activities of cells during the process of development. Once the balance between these processes is disrupted, a number of diseases may then develop (43). Malignant tumor cells exhibit excessive proliferation, as well as abnormal migratory and invasive ability and apoptosis $(44,45)$. Therefore, the identification of targeted genes associated with these processes are of utmost importance. According to GO annotation, MCM6 plays a key role in DNA replication initiation and in the G1/S transition of the mitotic cell cycle, which were validated in later experiments (18). In the present study, following transfection of the EC109 and KYSE30 cells with siRNA-MCM6\#1 and siRNA-MCM6\#2, CCK8, wound-healing and Transwell assays (with or without Matrigel) and flow cytometry were performed to determine the cell proliferative, migratory and invasive ability, as well as cell apoptosis and the progression of the cell cycle. The results indicated that the knockdown of MCM6 inhibited the cell proliferative, migratory and invasive ability, and promoted cell apoptosis; the cell cycle assay also revealed that the cells were arrested at the $\mathrm{S}$ stage. These results suggested that MCM6 affected the proliferation, migration and invasion, and the apoptosis of EC cells.

In conclusion, the present study identified 24 DEGs between ESCC and normal esophagus tissues by bioinformatics analysis, and MCM6 was identified as the most important gene in the network. Several other websites also validated the elevated MCM6 expression, and IHC and RT-qPCR experimental validation also confirmed the upregulation in ESCC, compared with normal tissues or cell lines. Additionally, cell proliferation, cell migration and invasion, and cell apoptosis assays suggested that MCM6 plays an important role in the progression of ESCC.

\section{Acknowledgements}

We acknowledge the researchers for providing their GEO database information online and their contributions to the database.

\section{Funding}

The study was supported by the Henan Provincial Department of Education Key Science and Technology Project (grant no. 18A320007), the Ministry of Health and Welfare Committee (grant no. SBGJ2018013) and Key Medical Science and Technology Project of Health Department (grant no. 201503008).

\section{Availability of data and materials}

The datasets used and/or analyzed during the current study are available in this published article.

\section{Authors' contributions}

$\mathrm{XL}$ and JG designed the study, and XL wrote the manuscript and contributed to the analysis or interpretation of the data. $\mathrm{ZR}, \mathrm{CX}$ and CL participated in the experiment performing and the revision of the manuscript. YL provided the design of the study and analysis of the data. CR provided the laboratory support, analysis and interpretation of data and the direction of experiment performing. As the corresponding author, HL was responsible for the design of the experiments, the revision of the manuscript and final decision to submit the article for publication and also accountable for all aspects of the work. All authors have read and approved the final manuscript.

\section{Ethics approval and consent to participate}

This study was approved by the Ethics Committee of the First Affiliated Hospital of Zhengzhou University. All patients have signed informed consents.

\section{Patient consent for publication}

Not applicable. 


\section{Competing interests}

The authors declare that they have no competing interests.

\section{References}

1. Siewert JR and Ott K: Are squamous and adenocarcinomas of the esophagus the same disease? Semin Radiat Oncol 17: 38-44, 2007.

2. Chen W, Zheng R, Baade PD, Zhang S, Zeng H, Bray F, Jemal A, Yu XQ and He J: Cancer statistics in China, 2015. CA Cancer J Clin 66: 115-132, 2016.

3. Jemal A, Center MM, DeSantis C and Ward EM: Global patterns of cancer incidence and mortality rates and trends. Cancer Epidemiol Biomarkers Prev 19: 1893-1907, 2010

4. Zeng H, Zheng R, Zhang S, Zuo T, Xia C, Zou X and Chen W: Esophageal cancer statistics in China, 2011: Estimates based on 177 cancer registries. Thorac Cancer 7: 232-237, 2016.

5. Xing D, Tan W and Lin D: Genetic polymorphisms and susceptibility to esophageal cancer among Chinese population (review) Oncol Rep 10: 1615-1623, 2003.

6. Domper Arnal MJ, Ferrández Arenas Á and Lanas Arbeloa Á: Esophageal cancer: Risk factors, screening and endoscopic treatment in Western and Eastern countries. World J Gastroenterol 21 7933-743, 2015.

7. Wang L, Xiong Y, Sun Y, Fang Z, Li L, Ji H and Shi T: HLungDB: An integrated database of human lung cancer research. Nucleic Acids Res 38 (Database Issue): D665-D669, 2010.

8. Hirano H and Kato K: Systemic treatment of advanced esophageal squamous cell carcinoma: Chemotherapy, molecular-targeting therapy and immunotherapy. Jpn J Clin Oncol 49: 412-420, 2019.

9. Deng HY, Wang WP, Wang YC, Hu WP, Ni PZ, Lin YD and Chen LQ: Neoadjuvant chemoradiotherapy or chemotherapy? A comprehensive systematic review and meta-analysis of the options for neoadjuvant therapy for treating oesophageal cancer. Eur J Cardiothorac Surg 51: 421-431, 2017.

10. Talukdar FR, di Pietro M, Secrier M, Moehler M, Goepfert K, Lima SSC, Pinto LFR, Hendricks D, Parker MI and Herceg Z: Molecular landscape of esophageal cancer: Implications for early detection and personalized therapy. Ann N Y Acad Sci 1434 342-359, 2018

11. Aibar S, Abaigar M, Campos-Laborie FJ, Sánchez-Santos JM, Hernandez-Rivas JM and De Las Rivas J: Identification of expression patterns in the progression of disease stages by integration of transcriptomic data. BMC Bioinformatics 17 (Suppl 15): S432, 2016

12. Golding GB: DNA and the revolutions of molecular evolution, computational biology, and bioinformatics. Genome 46: 930-935, 2003 .

13. Larson RS (eds): Bioinformatics and drug discovery. Second edition. Mathods Mol Biol 910, 2012.

14. Gaulton A, Bellis LJ, Bento AP, Chambers J, Davies M, Hersey A Light Y, McGlinchey S, Michalovich D, Al-Lazikani B and Overington JP: ChEMBL: A large-scale bioactivity database for drug discovery. Nucleic Acids Res 40 (Database Issue) D1100-D1107, 2012

15. Tanya B, Troup DB, Wilhite SE, Ledoux P, Evangelista C, Kim IF, Tomashevsky M, Marshall KA, Phillippy KH Sherman PM, et al: NCBI GEO: Archive for functional genomics data sets-10 years on. Nucleic Acids Res 39 (Database Issue) D1005-D1010, 2011.

16. Edgar R, Domrachev M and Lash AE: Gene expression omnibus: NCBI gene expression and hybridization array data repository. Nucleic Acids Res 30: 207-210, 2002.

17. Tye BK: MCM proteins in DNA replication. Annu Rey Biochem 68: 649-686, 1999.

18. Forsburg SL: Eukaryotic MCM proteins: Beyond replication initiation. Microbiol Mol Biol Rev 68: 109-131, 2004.

19. Fitch MJ, Donato JJ and Tye BK: Mcm7, a subunit of the presumptive MCM helicase, modulates its own expression in conjunction with Mcm1. J Biol Chem 278: 25408-25416, 2003.

20. Chong JP, Mahbubani HM, Khoo CY and Blow JJ: Purification of an MCM-containing complex as a component of the DNA replication licensing system. Nature 375: 418-421, 1995.

21. Gauchotte G, Vigouroux C, Rech F, Battaglia-Hsu SF, Soudant M, Pinelli C, Civit T, Taillandier L, Vignaud JM and Bressenot A Expression of minichromosome maintenance MCM6 protein in meningiomas is strongly correlated with histologic grade and clinical outcome. Am J Surg Pathol 36: 283-291, 2012.
22. Vigouroux C, Casse JM, Battaglia-Hsu SF, Brochin L, Luc A, Paris C, Lacomme S, Gueant JL, Vignaud JM and Gauchotte G: Methyl(R217)HuR and MCM6 are inversely correlated and are prognostic markers in non small cell lung carcinoma. Lung Cancer 89: 189-196, 2015.

23. Helfenstein A, Frahm SO, Krams M, Drescher W, Parwaresch R and Hassenpflug J: Minichromosome maintenance protein (MCM6) in low-grade chondrosarcoma: Distinction from enchondroma and identification of progressive tumors. Am J Clin Pathol 122: 912-918, 2004.

24. Hotton J, Agopiantz M, Leroux A, Charra-Brunaud C, Marie B, Busby-Venner H, Morel O, Guéant JL, Vignaud JM, Battaglia-Hsu SF and Gauchotte G: Minichromosome maintenance complex component 6 (MCM6) expression correlates with histological grade and survival in endometrioid endometrial adenocarcinoma. Virchows Arch 472: 623-633, 2018.

25. Hendricks A, Gieseler F, Nazzal S, Bräsen JH, Lucius R, Sipos B Claasen JH, Becker T, Hinz S, Burmeister G, et al: Prognostic relevance of topoisomerase II $\alpha$ and minichromosome maintenance protein 6 expression in colorectal cancer. BMC Cancer 19: 429, 2019.

26. Liu M, Hu Q, Tu M, Wang X, Yang Z, Yang G and Luo R: MCM6 promotes metastasis of hepatocellular carcinoma via MEK/ERK pathway and serves as a novel serum biomarker for early recurrence. J Exp Clin Cancer Res 37: 10, 2018.

27. Zheng T, Chen M, Han S, Zhang L, Bai Y, Fang X, Ding SZ and Yang Y: Plasma minichromosome maintenance complex component 6 is a novel biomarker for hepatocellular carcinoma patients. Hepatol Res 44: 1347-1356, 2014

28. Shade A and Handelsman J: Beyond the Venn diagram: The hun for a core microbiome. Environ Microbiol 14: 4-12, 2012

29. Szklarczyk D, Morris JH, Cook H, Kuhn M, Wyder S, Simonovic M, Santos A, Doncheva NT, Roth A, Bork P, et al: The STRING database in 2017: Quality-controlled protein-protein association networks, made broadly accessible. Nucleic Acids Res 45 (D1): D362-D368, 2017.

30. Szklarczyk D, Franceschini A, Wyder S, Forslund K, Heller D, Huerta-Cepas J, Simonovic M, Roth A, Santos A, Tsafou KP, et al: STRING v10: Protein-protein interaction networks, integrated over the tree of life. Nucleic Acids Res 43 (Database Issue): D447-D452, 2015.

31. Shannon P, Markiel A, Ozier O, Baliga NS, Wang JT, Ramage D, Amin N, Schwikowski B and Ideker T: Cytoscape: A software environment for integrated models of biomolecular interaction networks. Genome Res 13: 2498-2504, 2003.

32. Huang da W, Sherman BT and Lempicki RA: Systematic and integrative analysis of large gene lists using DAVID bioinformatics resources. Nat Protoc 4: 44-57, 2009.

33. Gene Ontology Consortium: The gene ontology (GO) project in 2006. Nucleic Acids Res 34 (Database Issue): D322-D326, 2006

34. Kanehisa M and Goto S: KEGG: Kyoto encyclopaedia of genes and genomes. Nucleic Acids Res 28: 27-30, 2000.

35. Rhodes DR, Kalyana-Sundaram S, Mahavisno V, Varambally R, Yu J, Briggs BB, Barrette TR, Anstet MJ, Kincead-Beal C, Kulkarni P, et al: Oncomine 3.0: Genes, pathways, and networks in a collection of 18,000 cancer gene expression profiles. Neoplasia 9: 166-180, 2007.

36. Tang Z, Li C, Kang B, Gao G, Li C and Zhang Z: GEPIA: A web server for cancer and normal gene expression profiling and interactive analyses. Nucleic Acids Res 45 (W1): W98-W102, 2017.

37. Chandrashekar DS, Bashel B, Balasubramanya SAH, Creighton CJ, Ponce-Rodriguez I, Chakravarthi BVSK and Varambally S: UALCAN: A portal for facilitating tumor subgroup gene expression and survival analyses. Neoplasia 19: 649-658, 2017.

38. Livak KJ and Schmittgen TD: Analysis of relative gene expression data using real-time quantitative PCR and the 2(-Delta Delta $\mathrm{C}(\mathrm{T})$ ) method. Methods 25: 402-408, 2001

39. do Valle ÍF, Menichetti G, Simonetti G, Bruno S, Zironi I, Durso DF, Mombach JCM, Martinelli G, Castellani G and Remondini D: Network integration of multi-tumour omics data suggests novel targeting strategies. Nat Commun 9: 4514, 2018.

40. Hashemifar S, Neyshabur B, Khan AA and Xu J: Predicting protein-protein interactions through sequence-based deep learning. Bioinformatics 34: i802-i810, 2018.

41. He W, Chen L, Yuan K, Zhou Q, Peng L and Han Y: Gene set enrichment analysis and meta-analysis to identify six key genes regulating and controlling the prognosis of esophageal squamous cell carcinoma. J Thorac Dis 10: 5714-5726, 2018. 
42. Zhang Y, Xu Y, Li Z, Zhu Y, Wen S, Wang M, Lv H, Zhang F and Tian Z: Identification of the key transcription factors in esophageal squamous cell carcinoma. J Thorac Dis 10: 148-161, 2018.

43. Ahmed AA, Mohamed AD, Gener M, Li W and Taboada E: YAP and the hippo pathway in pediatric cancer. Mol Cell Oncol 4: e1295127, 2017.

44. Hanahan D and Weinberg RA: Hallmarks of cancer: The next generation. Cell 144: 646-674, 2011

45. Hanahan D and Weinberg RA: The hallmarks of cancer. Cell 100: 57-70, 2000.

46. Saito S, Morishima K, Ui T, Hoshino H, Matsubara D, Ishikawa S, Aburatani H, Fukayama M, Hosoya Y, Sata N, et al: The role of HGF/MET and FGF/FGFR in fibroblast-derived growth stimulation and lapatinib-resistance of esophageal squamous cell carcinoma. BMC Cancer 15: 82, 2015.

47. Wang Q, Ma C and Kemmner W: Wdr66 is a novel marker for risk stratification and involved in epithelial-mesenchymal transition of esophageal squamous cell carcinoma. BMC Cancer 13: $137,2013$.

48. Lee JJ, Natsuizaka M, Ohashi S, Wong GS, Takaoka M, Michaylira CZ, Budo D, Tobias JW, Kanai M, Shirakawa Y, et al: Hypoxia activates the cyclooxygenase-2-prostaglandin E synthase axis. Carcinogenesis 31: 427-434, 2010.

49. Erkizan HV, Johnson K, Ghimbovschi S, Karkera D, Trachiotis G, Adib H, Hoffman EP and Wadleigh RG: African-American esophageal squamous cell carcinoma expression profile reveals dysregulation of stress response and detox networks. BMC Cancer 17: 426, 2017.

50. Su H, Hu N, Yang HH, Wang C, Takikita M, Wang QH, Giffen C, Clifford R, Hewitt SM, Shou JZ, et al: Global gene expression profiling and validation in esophageal squamous cell carcinoma and its association with clinical phenotypes. Clin Cancer Res 17: 2955-2966, 2011.
51. Hu N, Clifford RJ, Yang HH, Wang C, Goldstein AM, Ding T, Taylor PR and Lee MP: Genome wide analysis of DNA copy number neutral loss of heterozygosity $(\mathrm{CNNLOH})$ and its relation to gene expression in esophageal squamous cell carcinoma. BMC Genomics 11: 576, 2010.

52. Kimchi ET, Posner MC, Park JO, Darga TE, Kocherginsky M, Karrison T, Hart J, Smith KD, Mezhir JJ, Weichselbaum RR and Khodarev NN: Progression of Barrett's metaplasia to adenocarcinoma is associated with the suppression of the transcriptional programs of epidermal differentiation. Cancer Res 65: 3146-3154, 2005.

53. Wang S, Zhan M, Yin J, Abraham JM, Mori Y, Sato F, Xu Y, Olaru A, Berki AT, Li H, et al: Transcriptional profiling suggests that Barrett's metaplasia is an early intermediate stage in esophageal adenocarcinogenesis. Oncogene 25: 3346-3356, 2006.

54. Hao Y, Triadafilopoulos G, Sahbaie P, Young HS, Omary MB and Lowe AW: Gene expression profiling reveals stromal genes expressed in common between Barrett's esophagus and adenocarcinoma. Gastroenterology 131: 925-933, 2006.

55. Kim SM, Park YY, Park ES, Cho JY, Izzo JG, Zhang D, Kim SB, Lee JH, Bhutani MS, Swisher SG, et al: Prognostic biomarkers for esophageal adenocarcinoma identified by analysis of tumor transcriptome. PLoS One 5: e15074, 2010.

This work is licensed under a Creative Commons Attribution-NonCommercial-NoDerivatives 4.0 International (CC BY-NC-ND 4.0) License. 